\title{
NUTRIÇÃO MINERAL DE HORTALIÇAS. XXI. Absorção de Nutrientes por Cultivares Nacionais de Batatinha (Solanum Tuberosum L.)
}

\author{
M. C. Motta Macedo ** \\ H. P. Haag *** \\ J. R. Gallo ****
}

\section{RESUMO}

O trabalho teve como objetivo verificar as diferencas na acumulação da matéria seca, absorção e distribuição de nutrientes, entre os cultivares nacionais de batatinha: ARACY, ITAIQUARA, ABAETE, TEBERE, IAC - 5555 e IAC - 5603.

O experimento foi conduzido em condições de campo, de outubro de 1974 a janeiro de 1975, na Estação Experimental de Capão Bonito, do Instituto Agronômico do Estado de São Paulo, em solo do grande grupo Latossol Vermelho Escuro fase orto. Utilizou-se uma adubação $\mathrm{N}-\mathrm{P}_{2} \mathrm{O}_{5}-\mathrm{K}_{6} \mathrm{O}$ de 70-300-105 kg/ha no plantio e $70 \mathrm{Kg} / \mathrm{ha}$ de nitrogênio em cobertura 45 dias após.

As plantas foram amostradas durante o desenvolvimento da cultura em intervalos de 20 dias a partir da germinação até a seca das folhas e hastes. Analisou-se, na matéria seca, os teores de nitrogênio, fósforo, potássio, cálcio, magnésio, enxofre, cobre e ferro. As curvas da marcha de absorção dos nutrientes e produção de matéria seca foram obtidas a partir de dados calculados por equações de regressão ajustadas. Considerou-se como quantidades extraídas. O delineamento estatístico foi o de blocos ao acaso.

Detectou-se diferenças significativas na produção de matéria seca, absorção de nutrientes e na exportação de nutrientes. O cultivar IAC - 5603 foi o mais precoce na produção de tuberculos, tendo sido os cultivares mais tardios ABAETE e TEBERE.

* Parte da dissertação na obtenção do grau de Mestre pela ESALQ-USP apresentada pelo primeiro autor. Entregue para publicação em 23-09-1977.

** EMBRAPA, Babia.

*** Departamento de Química, ESALQ-USP, Piracicaba, SP.

**** Instituto Agronômico do Estado de São Paulo, SP. 


\section{INTRODUÇÃO}

A batatinha (Solanum Tuberosum L.) é uma planta predominante de clima temperado, mas a sua área de plantio em regiões tropicais e subtropicais, como na América Central, do Sul e Africa, tem aumentado em função de sua alta capacidade de adaptação ao meio (FAO Production Yearbook - 1971).

O Brasil é o principal produtor da América do Sul, porém o rendimento médio de $6.185 \mathrm{~kg} / \mathrm{ha} \mathrm{(I.B.G.E.} \mathrm{-} \mathrm{1973)} \mathrm{ainda} \mathrm{é} \mathrm{muito} \mathrm{bai-}$ xo, se considerarmos que em algumas áreas do País, agricultores adiantados chegam ao redor de 20.000 a $25.000 \mathrm{~kg} / \mathrm{ha}$. Para isso contribui principalmente a qualidade da semente e a adubação empregada, resepctivamente com $38 \%$ e $2 \%$ dos custos de produção (I.E.A. 1975) .

Os estudos entre nós, de nutrição mineral e adubação da batatinha foram principalmente feitos com relação à cultivares importados. Portanto estudos com cultivares nacionais de batatinha assumem uma grande importância, mormente agora em que estamos envidando esforços no sentido de produzirmos "batata-semente" nacional em escala comercial.

Verificar em cultivares nacionais de batatinha aspectos das necessidades minerais e capacidade de utilização de nutrientes, notadamente em se tratando de uma cultura que os exige em grande quantidade, revela-se de grande importância.

As possibilidades de selecionarmos plantas com capacidade de absorver, translocar ou utilizar eficientemente determinados nutrientes são fatos já citados na literatura (VOSE, 1963; EPSTEIN, 1972). Este último ( comenta, que existem grandes evidências de uma riqueza ilimitada de genótipos onde se pode extrair um grande número de variedades que preencham as mais diferentes necessidades.

Apesar da batatinha ser uma planta bastante estudada, trabalhos específicos sobre nutrição mineral, como omissão de nutrientes e níveis adequados são relativamente escassos na literatura.

Resumimos na tabela 1 os teores de concentração dos nutrientes estudados, citados na literatura, em diferentes partes da planta, condições de cultivo, épocas de amostragem e critérios de interpretação.

Como podemos verificar o nitrogênio é dos elementos mais estudados e os dados obtidos em campo prevalecem sobre os demais. 
As referências sobre micronutrientes de uma forma geral são restritas e se restringem mais a teores nos tubérculos. Estudos específicos sobre teores adequados e exigidos são raros na literatura (ver tabela 1).

Apresentamos na tabela 2 um sumário de revisão sobre a extração de nutrientes pela batatinha.

Verificamos que existem diferenças acentuadas nos dados observados por diversos autores, notadamente por ferem trabalhado com cultivares, condições edáficas e climáticas, tratos culturais, variados.

O melhoramento genético das plantas cultivadas, e em particular, o da batatinha, tem conseguido resultados surpreendentes com relação à plantas resistentes à pragas, doenças e condições climáticas adversas (MIRANDA, 1973).

KUNKEL et alii (1968), em vários experimentos realizados, coletaram pecíolos maduros de diferentes cultivares de batatinha de alta e baixa produção, tendo verificado que não havia diferença nas concentrações dos elementos: $\mathrm{N}, \mathrm{P}, \mathrm{K}$ e $\mathrm{Mg}$. As diferenças foram mais acentuadas para o tamanho das plantas e para o total de nutrientes extraídos pelos cultivares.

KUNKEL e HOLSTAD (1970), encontraram diversos clones de batatinha altamente produtivos que possuíam uma baixa porcentagem dos elementos: N, P, K, Ca e Mg nos pecíolos, aos 100 dias de idade.

BOOCK e PAIVA NETO (1950), trabalhando com 10 cultivares de batatinha, em 6 locais do Estado de São Paulo, encontraram uma variação muito reduzida na concentração de macronutrientes $(\mathrm{P}, \mathrm{K}, \mathrm{Ca}$ e Mg) na polpa e casca do tubérculo, apesar de terem ocorrido diferenças no volume de produção. Infelizmente, os dados não permitem umarecalculagem para se verificar as possíveis diferenças na exportação de nutrientes pelos diversos cultivares.

SMITH (1968), diz que as diferenças de absorção de nutrientes entre cultivares de batatinha não é muito grande. Cultivares de maturação precoce necessitariam de grande quantidade de nutrientes, no início do crescimento, enquanto que os tardios no final do crescimento. Porém, o total necessário, geralmente é bem maior para cultivares tardios do que para os precoces de maturação:

HAWKINS (1942), trabalhando com quatro cultivares de ciclo tardio absorveram cerca de $\mathrm{Kg} / \mathrm{ha}$ a mais do total de macronutrientes ( $\mathrm{N}, \mathrm{P}, \mathrm{K}, \mathrm{Ca}, \mathrm{Mg}$ e S), do que os de maturação precoce.

Propomo-nos, verificar as possíveis diferenças nutricionais entre os cultivares nacionais: ARACY, ITAIQUARA, ABAETE, IAC-5555 e IAC-5603, nos seguintes aspectos: 


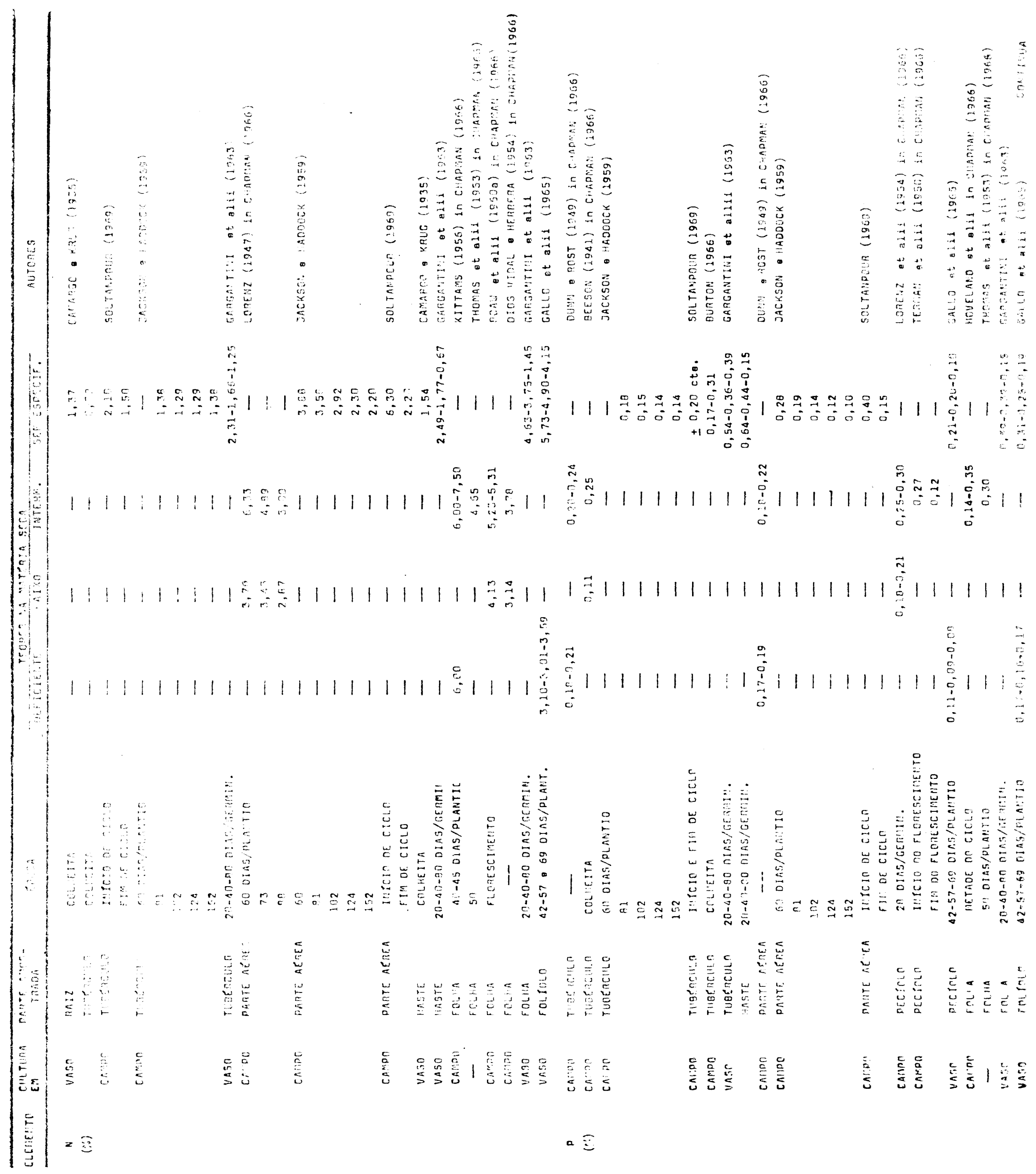




\begin{tabular}{|c|c|c|c|c|c|c|c|c|}
\hline $\mathrm{x}$ & reno & Tugersulo & COLHEITA & - & - & - & $1,0:-2,53$ & 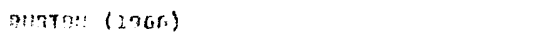 \\
\hline \multirow[t]{22}{*}{ (\%) } & \multirow[t]{4}{*}{ C: $D 0$} & Tubencle & $60 \mathrm{DinS/OLATITIS}$ & - & - & - & - & \multirow{5}{*}{ 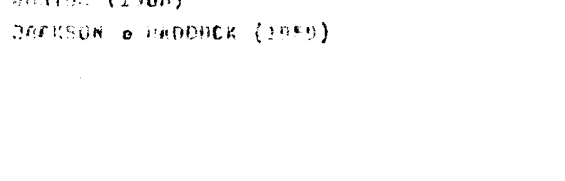 } \\
\hline & & & 8i & - & - & $\longrightarrow$ & 1,03 & \\
\hline & & & 202 & - & - & - & $3,5.9$ & \\
\hline & & & $\begin{array}{l}124 \\
152\end{array}$ & - & - & - & 1,59 & \\
\hline & 9053 & T:BTRE:ULO & $\begin{array}{l}152 \\
20-43-50 \text { and }\end{array}$ & $\overline{-}$ & - & - & 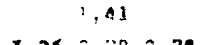 & \\
\hline & Yaso & $\begin{array}{l}\text { TUB?RLOLO } \\
\text { inste }\end{array}$ & 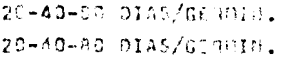 & $\overline{-}$ & - & - & $\begin{array}{l}3,25-2,78-2,78 \\
9,20-6,96-5,55\end{array}$ & nogurnuld at alii (1nas) \\
\hline & UESO & WASTE & 5) 0 : & $<2,03$ & - & 4,50 & $9,70-6,96-5,55$ & 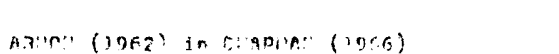 \\
\hline & $5 x \cdot 0$ & pecoson & 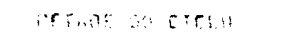 & - & - & 7,8 & - & 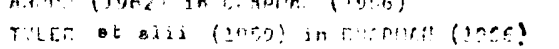 \\
\hline & $\operatorname{conos}$ & perto.o & $35-63$ niasper & 7,00 & $700-4,00$ & $>9,50$ & - & 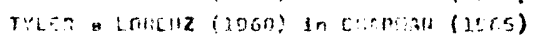 \\
\hline & 1050 & $0<0<0$ & 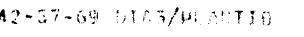 & & - & - & $7,32-6,0:-4,75$ & EALLE ot alis (ing5) \\
\hline & \multirow{4}{*}{ Caine } & \multirow[t]{4}{*}{ DATEC ariea } & 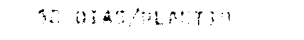 & - & - & - & 3,00 & \multirow{4}{*}{ 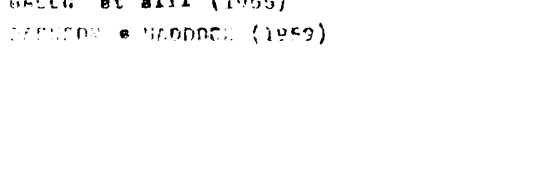 } \\
\hline & & & $\because 1$ & - & - & - & 2,91 & \\
\hline & & & $\therefore 2$ & - & - & - & 2,50 & \\
\hline & & & $\because 4$ & - & - & - & 1,77 & \\
\hline & $\cos \rightarrow 0$ & roins & 1,2 & $3,0 a-3,51$ & - & $5, \overline{0,-6,79}$ & 0.65 & rances o \\
\hline & cang & $\begin{array}{l}r 01 \cdots \\
r 04 \cdots\end{array}$ & $\overline{-}$ & $1,20-2,10$ & - & $2,10-3,80$ & - & $\begin{array}{l}\text { JOMES O PLAN (COAZ) in EHADMAM (1968) } \\
\text { LARME (J9A5A) }\end{array}$ \\
\hline & enen & reicisis & $\ldots$ & $1,55-5,10$ & - & $5,30-6,54$ & - & N.CHOLAS a YWES (1541) In CHAMMAM (2966) \\
\hline & anro & Fot:1A & - & $0,38-0,44$ & - & 1.60 & - & 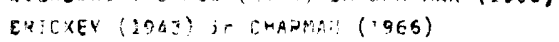 \\
\hline & $1: a 0$ & $=0 . \mathrm{A} A$ & - & $0,30-0,50$ & - & $4,1 \div-6,72$ & - & HEWIT of alis (anxi) in CHAPMAN (1966) \\
\hline & - & 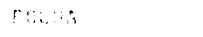 & 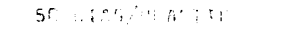 & - & - & 6,27 & - & THCMD: ot alis (2003) in CHNDMAN (1956) \\
\hline & inst & ratis & 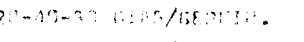 & $\cdots$ & - & - & $5, \cdots ;-5,5-3,54$ & GATSALTIUI ot olit (1963) \\
\hline & visn & rotion & 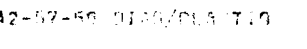 & & - & - & $3,22-2,54-2,02$ & FALLS ot alit (2005) \\
\hline ra & ching & Thentica & ENTHA & - & - & - & $0,03-n, 08$ & antar (2966) \\
\hline \multirow[t]{6}{*}{$(\boldsymbol{*})$} & \multirow[t]{3}{*}{ vann } & Turencitit & 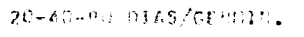 & - & - & - & $0,17-0,13-0,07$ & \multirow[t]{3}{*}{ EAFGRITHE et diti (1953) } \\
\hline & & moter. & 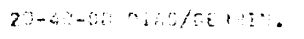 & - & - & - & $0,93-0,82-1,74$ & \\
\hline & & roinh & $26-4-80$ Das, & -- & - & - & $0,60-0,93-2,10$ & \\
\hline & chepn & 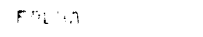 & - & $\therefore, 49$ & - & - & - & 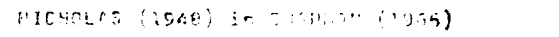 \\
\hline & $2 a+18$ & FOL & - & 0,71 & - & 3,30 & - & UASLACE (195:) in CHAP $(395)$ \\
\hline & caton & Folua & 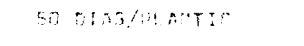 & - & - & 2,36 & - & 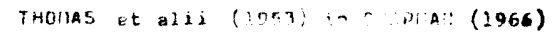 \\
\hline \multirow{15}{*}{$\begin{array}{l}m_{2} \\
(i 1)\end{array}$} & $\min 0$ & retentets & - & 10,12 & - & 8,13 & - & 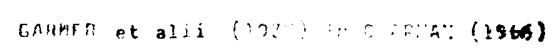 \\
\hline & : & Futratian & 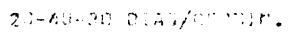 & - & - & - & $7,14-0,1,3-11,07$ & fnagnits: ot aldi (1): \\
\hline & $r a, 13$ & Thzentin & C.S. 19 : & - & - & - & $0,07-n, 14$ & Buitim (In:R) \\
\hline & ca: pn & wope & - & $0,13,0,14$ & - & $0,16-0,17$ & - & 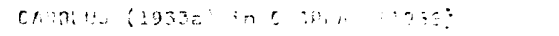 \\
\hline & ano & Magte & - & $0,20-0,30$ & - & $0,61-0,52$ & - & 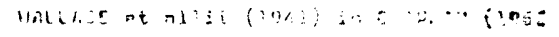 \\
\hline & ins? & $\therefore$ ints & 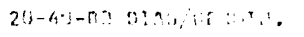 & -. & - & - & $0,40-0,44-0,27$ & 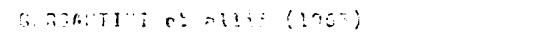 \\
\hline & Writ: & Mate If AR & - & $n, 06-0,13$ & - & $0,29-0,5 n$ & - & 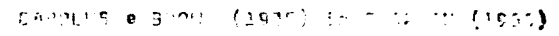 \\
\hline & \multirow[t]{2}{*}{ rishn } & rib:a suprargil & - & $0,12-0,22$ & - & $0,23-0,30$ & - & \multirow{2}{*}{ 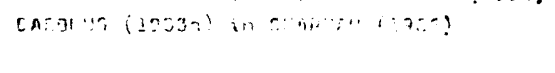 } \\
\hline & & 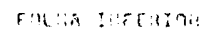 & - & $0,04-0,12$ & - & $0,16-0,25$ & - & \\
\hline & ving & rul:"a & - & $0.12-0.20$ & - & $0,28-0,66$ & - & 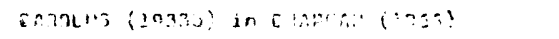 \\
\hline & crim: & rowini & - & $0,10-0,20$ & - & $0,37-0,40$ & - & 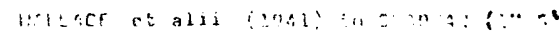 \\
\hline & $r ., n: p n$ & $\cdots n$ & - & $0,10-0,33$ & - & $8,40-0,86$ & - & 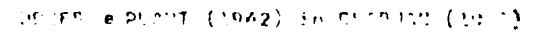 \\
\hline & 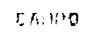 & Fmen: & - & $0,22-8,24$ & - & $0,40-0,78$ & - & 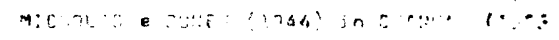 \\
\hline & - & rol a & 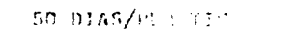 & - & - & 0,69 & - & 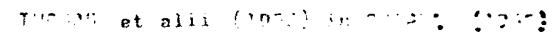 \\
\hline & whis: & ritan & 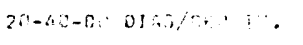 & - & - & - & $0,42-0,58-0,28$ & 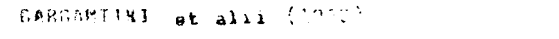 \\
\hline 5 & niso & rinear:: & 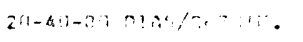 & - & $-\ldots$ & - & $0,32-0,24-7,23$ & SACGAMTINI et aisi (1063) \\
\hline \multirow[t]{3}{*}{ (3) } & eng & Mecractis & colistiti & - & - & $一$ & $0,11-0,21$ & BLATO (1900: \\
\hline & \multirow[t]{2}{*}{ ari } & an: & 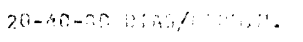 & - & - & $\ldots$ & $0,37-0,26-0,38$ & \multirow[t]{2}{*}{ Gnognifini et aliz $(1963)$} \\
\hline & & atis: & 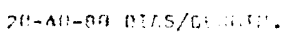 & - & - & - & $0,8:-0,03-0,93$ & \\
\hline c & ento & Tubeaculo & COLHEITA & - & - & - & $4,5-8,6$ & 9ureteri (1966) \\
\hline$(n n a)$ & into & FOLI.A & - & - & $2 n, 0$ & $3^{n}, 0-40,0$ & - & Hrace ot aill (1971) \\
\hline c.u & caneo & rubericuto & COLHEITA & - & - & - & $2,5-5,5$ & MADEF E BLODEETT (1935) \\
\hline$(\mathrm{pom})$ & EAMPO & Tuoercula & COLIEITA & - & - & - & $3,8-10,0$ & gURTON (1966) \\
\hline & - & Tunerieulo & COLHEITA & 2,5 & - & 5,0 & - & ENITT (1963) \\
\hline$\underset{(n g n)}{r \cdot}$ & 5:a:50 & Tusencuto & COLYEITA & - & - & - & $26,1-1 \cap 4,6$ & 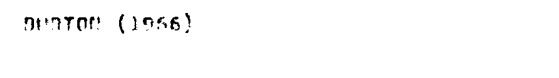 \\
\hline
\end{tabular}




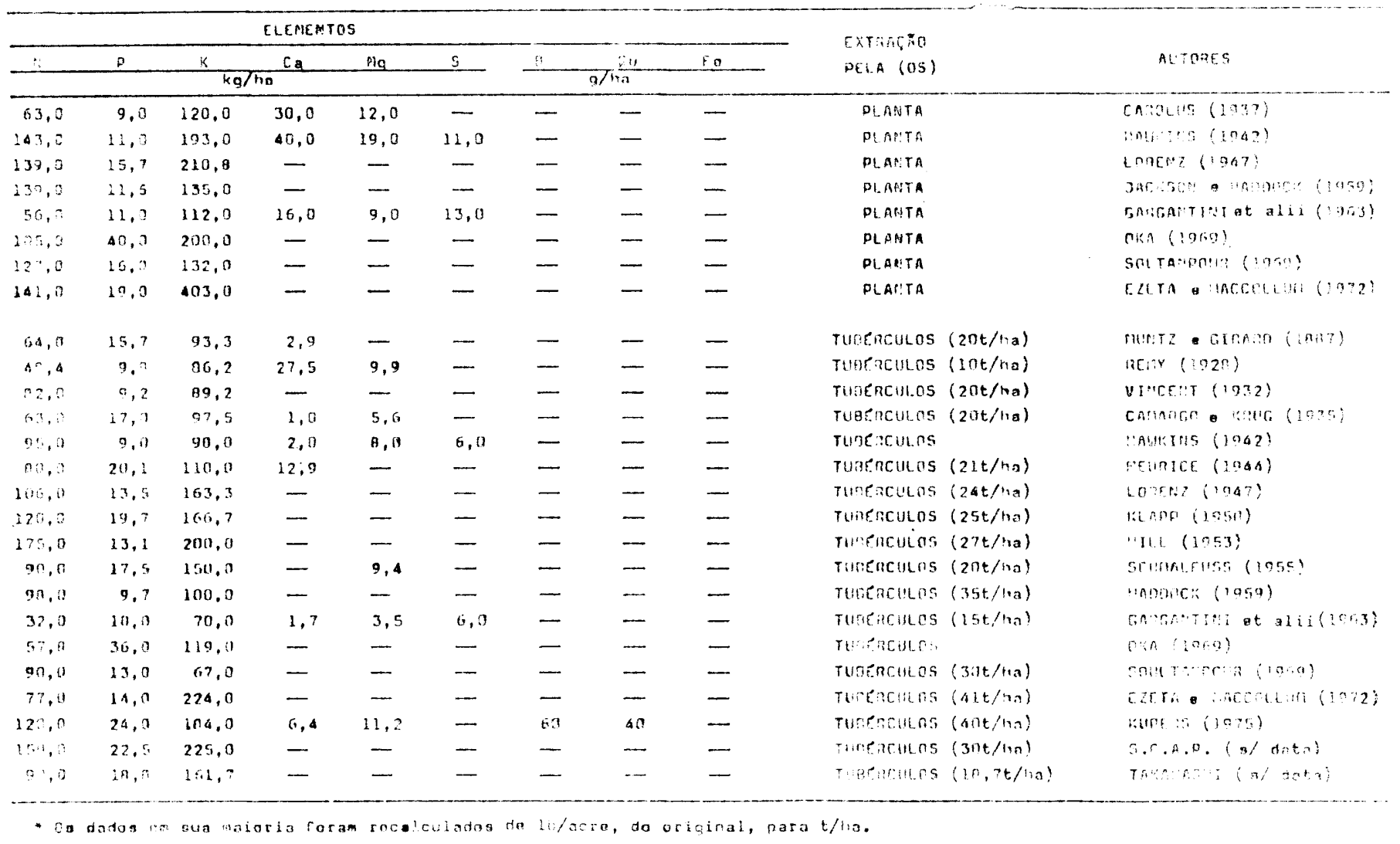

a) produção de matéria esca;

b) absorção dos nutrientes (N, P, K, Ca, Mg, S, Cu e Fe) em diversas fases do desenvolvimento;

c) exportação dos nutrientes;

d) produção de tubérculos.

\section{MATERIAL E MÉTODOS}

Os cultivares de batatinha (Solanum Tuberosum L.): ARACY (IAC-2), ITAIQUARA (IAC-3551), ABAETÊ (IAC-4183), TEBERE (IAC-4489), IAC-5555, IAC-5603, utizados, foram criados e selecionados pela Seção de Raízes e Tubérculos do Instituto Agronômico do Estado de São Paulo, Campinas.

As batatas-sementes utilizadas para plantio foram oriundas do mesmo local (Campos do Jordão, S.P.) e receberam os mesmos tratos culturais e condições de armazenagem.

O experimento foi instalado na Estação Experimental de Capão Bonito, do Instituto Agronômico do Estado de São Paulo, no município de Capão Bonito, situado a 240 00' 14" Lat. S e $48^{\circ} 20^{\prime}$ '54" Long. W (I.B.G.E., 1957) a $700 \mathrm{~m}$ de altitude, cujo clima segundo classificação de Koppen, é do tipo Cfb (SETZER, 1966). 
O solo do ensaio é classificado como Latossol Vermelho Escuro fase orto e as características químicas e granulométricas a camada arável acham-se na tabela 3. Tabela 3 - Resultados das analises química e granulométrica da camada arável.

Análise química*

\begin{tabular}{|c|c|c|c|c|c|}
\hline & & $\mathrm{AL}+++$ & $\mathrm{Ca}+++\mathrm{Mg}++$ & $\mathrm{K}+$ & $\mathrm{P}$ \\
\hline & orgânica & e. $\mathrm{mg} / 100 \mathrm{ml}$ & TFSA & $(\mathrm{kg} / \mathrm{ha})$ & TFSA \\
\hline 5,50 & 3,40 & 0,10 & 3,37 & 60 & 12 \\
\hline
\end{tabular}

Análise Granulométrica **

\begin{tabular}{ccccc} 
Argila & Limo & $\begin{array}{c}\text { Areia } \\
\text { fina } \\
\%\end{array}$ & $\begin{array}{c}\text { Areia } \\
\text { grossa } \\
\%\end{array}$ & Classificação \\
\hline 35,0 & 7,5 & 50,1 & 7,4 & Fino Areno \\
Argiloso
\end{tabular}

* Seção de Fertilidade do Solo - IAC, S.P.

** Seção de Pedologia - IAC, S.P.

As parcelas eram constituídas de 50 plantas cada, comopsta de 5 linhas de 10 plantas, cujo espaçamento foi de $0,80 \times 0,35 \mathrm{~m}$. Entre as parcelas havia uma linha de bordadura comum às mesmas. A adubação utilizada foi baseada na análise química do solo, segundo recomendações de CASTRO (1974), nas seguintes quantidades:

\begin{tabular}{lcc}
\hline Epoca & Elemento & $\begin{array}{c}\text { Quantidade } \\
(\mathrm{kg} / \mathrm{ha})\end{array}$ \\
\hline \multirow{2}{*}{ Plantio } & $\mathrm{N}$ & 70 \\
& $\mathrm{P}_{2} \mathrm{O}_{5}$ & 300 \\
\hline Cobertura (45 dias/plantio) & $\mathrm{K}_{2} \mathrm{O}$ & 105 \\
\hline
\end{tabular}

As fontes de fertilizantes foram sulfeto de amôneo, superfosfato simples e cloretos de potássio.

O controle das pragas e doenças foi executado aplicando-se no sulco de plantio um inseticida clorado 1 , e cerca de 7 pulverizações de uma mistura de inseticida fosforado 2 mais um fungicida a base de 
diditiocarbamato de zinco e manganês 3 e outro à base de estanho 4-, alternadamente.

As amostragens das plantas foram feitas em 5 épocas do desenvolvimento. A primeira, 20 dias após o início da germinação e as outras a intervalos de 20 dias até a seca das folhas e hastes. As plantas amostradas sempre o foram de tal forma que houvesse outras quatro competitivas ao redor.

Após a coleta, as plantas foram separadas nas partes: folhas (folíolos + pecíolos), hastes e tubérculos; pesadas e lavadas de acordo com as recomendações de SARRUGE e HAAG (1974) e postas à secar em estufa de circulação forçada de ar à $70-75^{\circ} \mathrm{C}$. Após a secagem, o material foi moído em moinho semi-micro Wiley, com peneira de 40 malhas/pol.

1 - Aldrin 5 (Aldrin 5\%) - Cia Nortox.

2 - Malatol 50 e (Malation 50\%) - Blenco Imp. e Exp. Ltda.

3 - Manzate D (Etileno bisditiocarbomato de manganês e zinco) - Dupont do Brasil S.A.

4 - Batasan (Trifenilacetato de estanho 20\%) - Blemco Imp. e Exp. Ltda.

As análises químicas do material foram determinadas para: nitrogêno e fósforo pelo Auto Analisador TECHNICON II, colorimetria, segundo CONCON e SOLTESS (1973), LOTT et alii (1956) e GEHRKE et alii (1973); potássio, cálcio e magnésio, enxofre, cobre e ferro, por espectrofotometria de absorção atômica, segundo PERKIN - ELMER (1971), BATAGLIA e GALLO (1972), BATAGLIA (1975) e GALLO et alii (1971), respectivamente. O boro foi analisado segundo método descrito em SARRUGE e HAAG (1974).

O delineamento estatístico foi o de blocos ao acaso com 4 repetições e 6 tratamentos (PIMENTEL GOMES, 1973).

\section{RESULTADOS E DISCUSSÃO}

\section{Crescimento}

Os dados referentes à produção de matéria seca pela planta e acumulação nos órgãos, pelos diferentes cultivares, em função do crescimento acham-se expressos na tabela 3 .

A análise da variância global desses dados apresentou os seguintes resultados: 


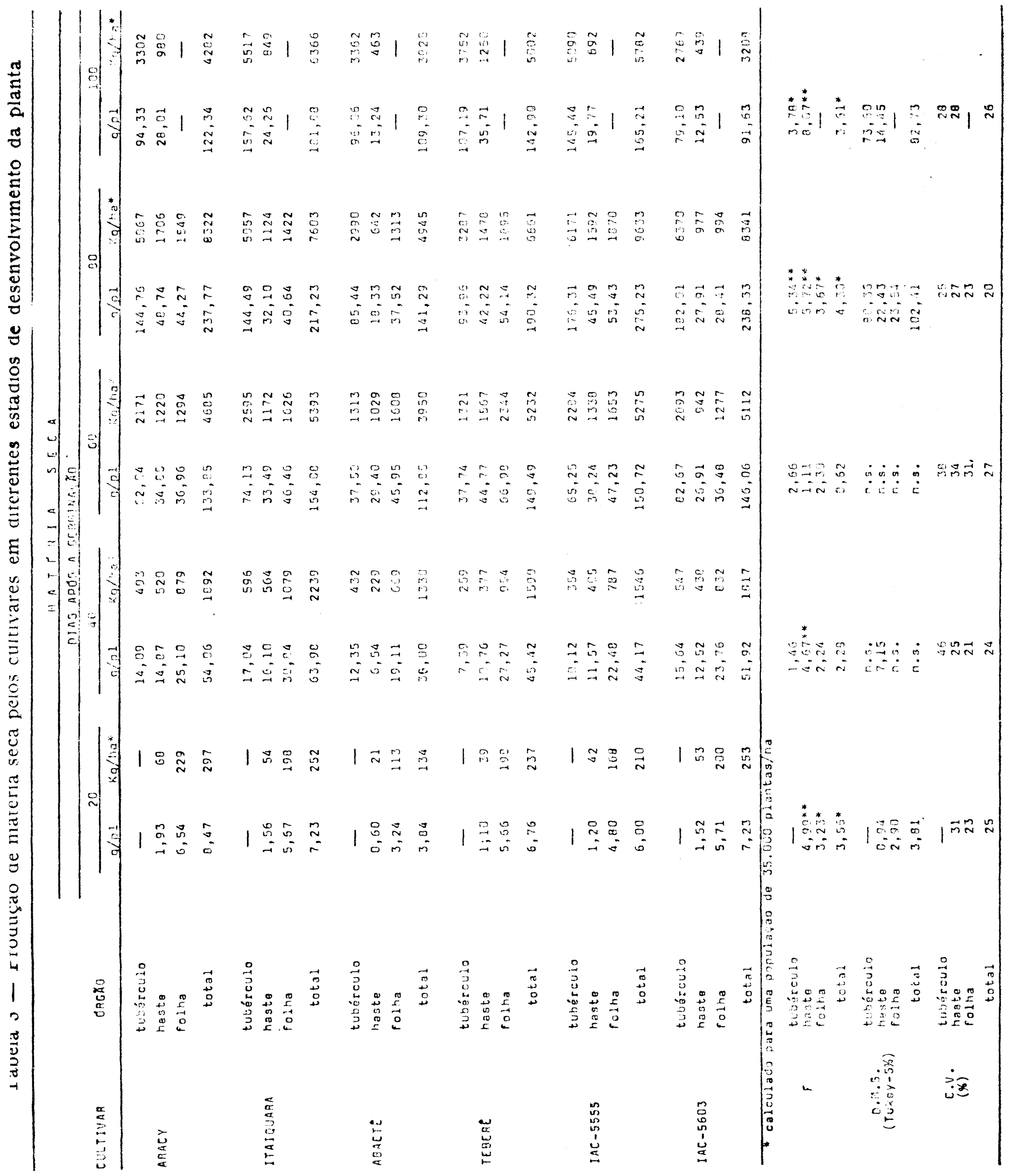




\begin{tabular}{lrcc}
\hline Causa de Variação & G.L. & Q.M. & F. \\
\hline Blocos & 3 & 1964,63 & 1,47 \\
Cultivares & 5 & 5650,04 & $4,23^{*}$ \\
Resíduo (A) & 15 & 1334,61 & 1,46 \\
\hline Parcelas & $(23)$ & & \\
Epocas & 4 & 164110,87 & $179,71^{* *}$ \\
Blocos x Epocas & 12 & 593,833 & 0,63 \\
Cult. x Epocas & 20 & 2232,66 & 2,44 \\
Resíduo (B) & 60 & 913,22 & 1,00 \\
\hline Total & 119 & &
\end{tabular}

Os cultivares diferiram ao nível de $50 \%$ de probabilidade na produção de matéria seca. A interação entre cultivares e épocas, significativa ao nível de $1 \%$, revelou uma diferença marcante entre cultivares e épocas de acumulação.

O ajuste das curvas de regressão recaiu, para todos os cultivares, sobre equações representativas de $3 .^{\circ}$ grau, apresentadas na figura 1 , demonstrando um formato sigmóide de acordo com os conceitos apresentados por BONNER e GALSTON (1952).

Apesar de todos os cultivares terem apresentado a mesma tendência de crescimento, as taxas de acumulação de matéria, nas épocas estudadas, foram diferentes. Dos 40 aos 60 e dos 60 aos 80 dias, o crescimento foi praticamente linear, tendo variado entre os cultivares de 131 a 186 e de 50 a $218 \mathrm{~kg} / \mathrm{ha} /$ dia, respectivamente.

Guardando-se as devidas proporções em razão do clima, ciclo vegetativo e tratos cultivares, as variações encontradas estão de acordo com as obtidas por SOLTANPOUR (1969), EZETA e MCCOLLUM (1972) e KUPERS (1975).

O ponto de máxima produção de matéria seca, em dias, e respectiva quantidade, assim como o ponto em que a taxa de acumulação passa a ser máxima, dados pelas equações ajustadas, foram os seguintes: 


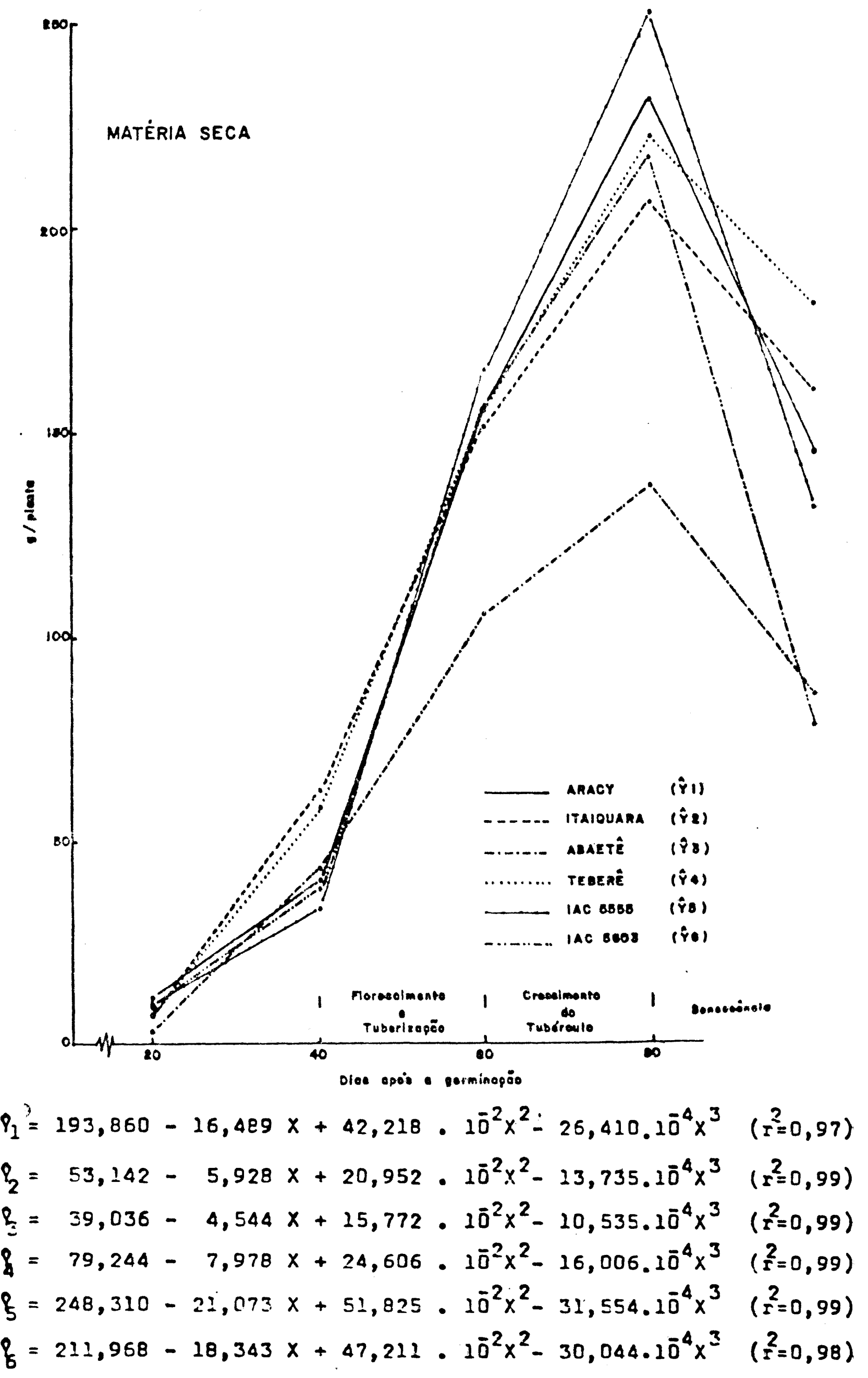

Fig. 1 - Curvas representativas do crescimento de matéria seca em g/planta $(Y)$ em função da idade (X) dos cultivares. 


\begin{tabular}{|c|c|c|c|c|}
\hline \multirow{2}{*}{ Cultivar } & \multirow{2}{*}{$\begin{array}{l}\text { Ponto de } \\
\text { Máximo } \\
\text { (dias) }\end{array}$} & \multicolumn{2}{|c|}{ Quantidade Máxima } & \multirow{2}{*}{$\begin{array}{l}\text { Ponto de } \\
\text { Inflexão } \\
\text { (dias) }\end{array}$} \\
\hline & & (g/plantas & (kg/ha) & \\
\hline Aracy & 81 & 225 & 7860 & 53 \\
\hline Itaiquara & 85 & 225 & 7684 & 51 \\
\hline Abaetê & 82 & 146 & 5111 & 50 \\
\hline Teberê & 82 & 197 & 6896 & 51 \\
\hline IAC -5555 & 83 & 265 & 9286 & 55 \\
\hline $1 A C-5603$ & 79 & 228 & 7979 & 52 \\
\hline
\end{tabular}

Os dois cultivares que mais acumularam matéria seca, IAC-5555 e IAC-5603, respectivamente ( apresentaram pontos de máximo e de inflexão distintos, de acordo com os ciclos de maturação, sendo um tardio e o outro precoce.

As análises das partes vegetativas, nas épocas amostradas, mostraram haver maior significância no caso das hastes e na planta toda, do que para os tubérculos e folhas, como pode ser observado na tabela 3 . Os diferentes portes de plantas, principalmente com relação aos cultivares ARACY e ITAIQUARA, que possuem hastes mais longas e grossas, em contraposição à IAC-5603 e ABAETÊ, que além de hastes curtas e delgadas, possuem porte menor, sejam as causas das variações ocorridas.

A matéria seca acumulada nos tubérculos dos cultivare: ARACY, IAC-55555 e IAC-5603, como pode ser observadas na tabela 3, apresentou um decréscimo aos 100 dias após a germinação. Problemas de amostragem e diferentes épocas de maturação fisiológica dos cultivares talvez sejam os fatores que mais influenciaram o fenômeno.

A água, fator de grande importância na formação da matéria seca, representada pelas chuvas, apresentou uma distribuição um pouco mais elevada, notadamente no final do ciclo.

Em situações como essa, de maior densidade hídrica solos com características granulométricas como as do solo empregado, podem proporcionar condições de baixa aeração, que é revelada pela emissão de lenticelas, órgãos acessóricos de respiração, pelos tubérculos, promovendo uma taxa de respiração mais elevada e problemas de podridões locais causadas pela penetração de microrganismos.

O cultivar IAC-5603 aos 80 dias da germinação já apresentava externamente aspectos de maturação fisiológica, com muitas hastes e folhas secas. O período que decorreu daí, portanío, deve ter sido prejudicial à produçã̃o final, por ser bastante sensível aos problemas descritos. 
O suprimento de água e produção de matéria seca, relacionado com os problemas observados, encontra-se bem discutido em BURTON (1966) .

Queda na acumulação da matéria seca pelos tubérculos, em ensaios semelhantes também ocorreram com HAWKINS (1942) e GARGANTINI et alii (1963).

\section{MACRONUTRIENTES}

\section{Nitrogênio}

A concentração e extração de nitrogênio pelos cultivares em várias épocas do desenvolvimento, estão expostas na tabela 4 .

De acordo com a análise de variância global os dados apresentaram os seguintes resultados:

\begin{tabular}{lrrr}
\hline Causa de Variação & G.L. & Q.M. & F. \\
\hline Blocos & 3 & 1275411,66 & 2,84 \\
Cultivares & 5 & 2807845,83 & $6,24^{* *}$ \\
Resíduo (A) & 15 & 449649,60 & 0,95 \\
\hline Parcelas & $(23)$ & & \\
Epocas & 4 & 51245066,59 & $107,98^{* *}$ \\
Blocos x Epocas & 12 & 249232,41 & 0,53 \\
Cult. x Epocas & 20 & 680448,15 & 1,43 \\
Resíduo (B) & 60 & 474575,05 & 1,00 \\
\hline
\end{tabular}

Total

119

Os cultivares diferiram ao nível de $1 \%$ de probabilidade na extração de nitrogênio. A não significância da interaçãa cultivares x épocas, demonstrou que os mesmos independem da época para absorver diferencialmente o elemento, embora o façam em quantidades significativamente diferentes. 


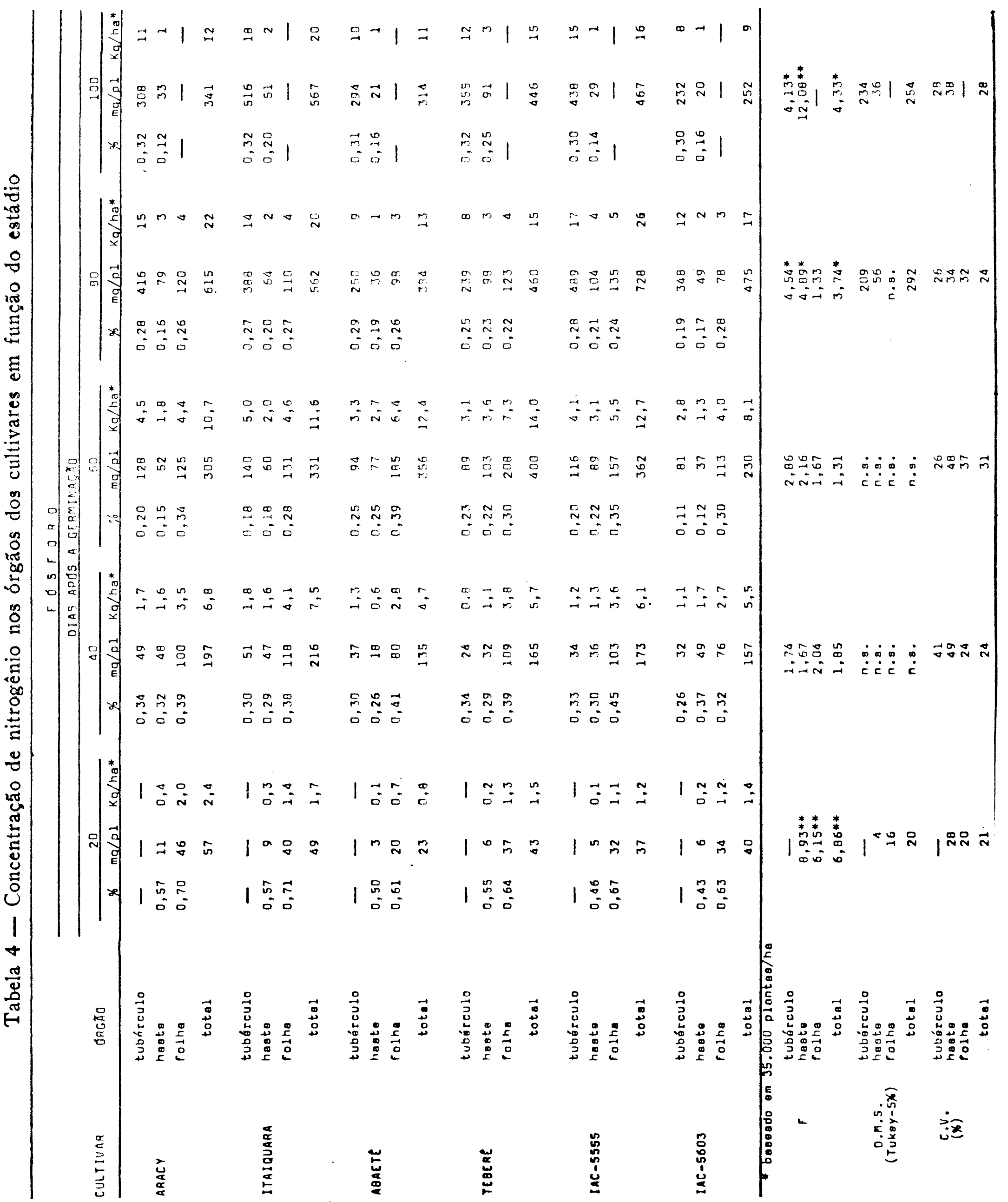


As equações ajustadas para as curvas de absorção de nitrogênio, pelos cultivares, estão expressas na figura 2. Com exceção dos cultivares ITAIQUARA e ABAETÊ, que se ajustaram à uma equação de $2^{\circ}$ grau, os demais o foram para de $3 .^{\circ}$.

A época compreendida entre o crescimento inicial das plantas até o final do florescimento foi aquela em que houve uma demanda maior do elemento.

Os cultivares que mais extraíram foram pela ordem decrescente: IAC-5555, TEBERE, ARACY, ITAIQUARA, IAC-5603 e ABAETÊ. De uma forma geral, essa tendência acompanhou a acumulação da matéria seca.

Os pontos de máxima absorção e demanđa, obtidos das aquações ajustadas, foram os seguintes:

\begin{tabular}{lcccc}
\hline Cultivar & $\begin{array}{c}\text { Ponto de } \\
\text { Máximo } \\
\text { (dias) }\end{array}$ & Quantidade & Máxima & $\begin{array}{c}\text { Ponto de } \\
\text { Inflexão } \\
\text { (dias) }\end{array}$ \\
\hline Aracy & 77 & 4651 & 163 & 49 \\
Itaicunara & 72 & 3870 & 135 & - \\
Abaetê & 70 & 2900 & 102 & - \\
Teberê & 76 & 4728 & 165 & 42 \\
IAC -5555 & 79 & 4746 & 166 & 49 \\
\hline IAC -5603 & 76 & 3511 & 123 & 46
\end{tabular}

Os cultivares tiveram em média aos 45 dias após a germinação, a época de exigência máxima. Essa observação vem confirmar os resultados obtidos por GARGANTINI et alii (1963), e reforçar as recomendações da Seção de Raízes e Tubérculos, do Instituto Agronômico (S.P.) quando sugere a aplicação parcelada do adubo nitrogenado.

As quantidades de nitrogênio extraídas variaram, entre cultivares, de 102 a $166 \mathrm{~kg} / \mathrm{ha}$. Essas quantias, de acordo com o volume de produção, e dose de fertilizante aplicada estão de acordo com as citadas na revisão de literatura.

Os cultivares de ciclo de maturação mais tardio, como ARACY, TEBERÊ e IAC-5555, confirmando as observações de SMITH (1968), após os 60 dias, continuaram absorvendo o nutriente numa taxa mais elevada que os demais. 


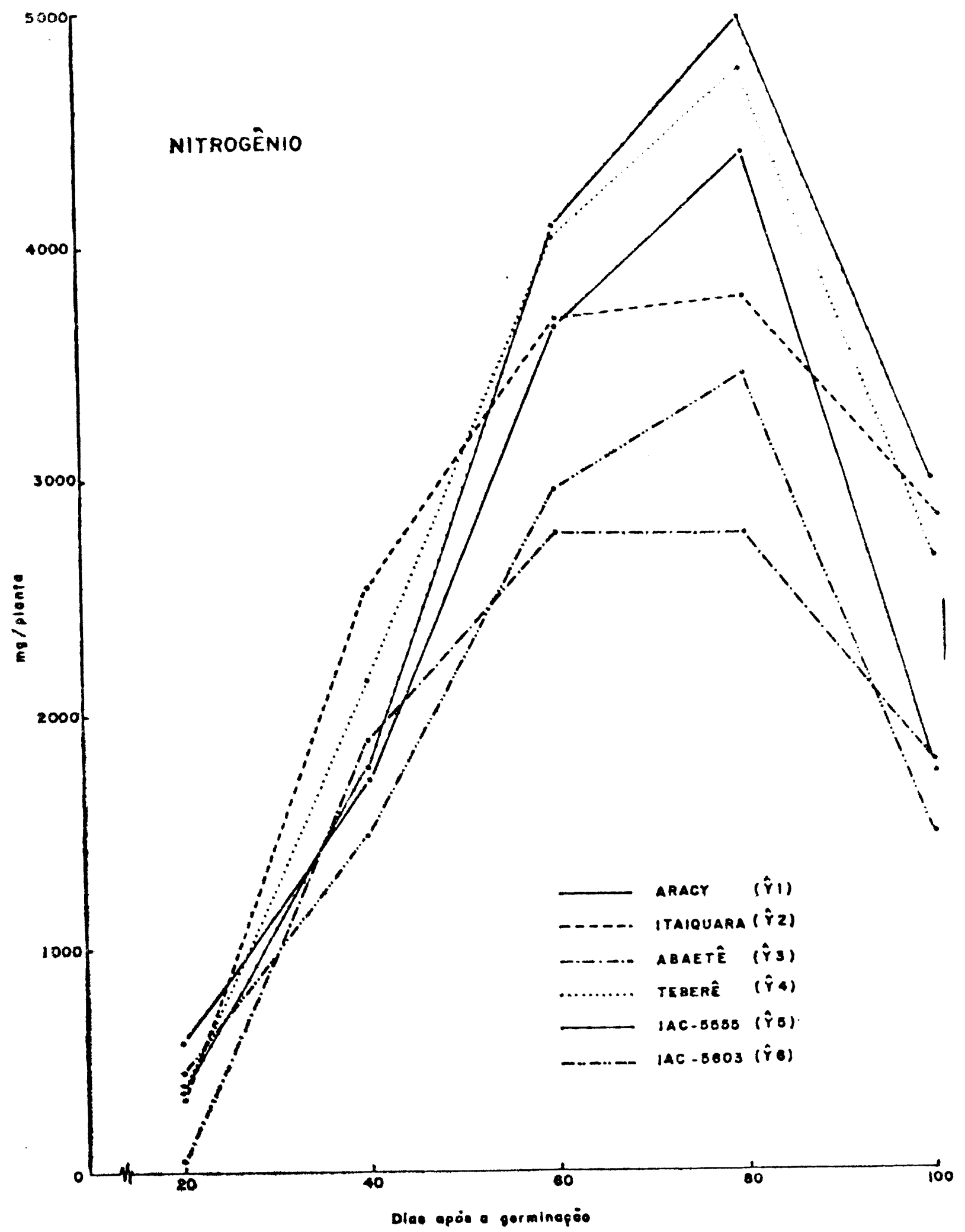

Fig. 2 - Curvas representativas da absorção de nitrogênio $\mathrm{mg} / \mathrm{planta}(\hat{\mathrm{Y}})$ em função de idade (X) dos cultivares 
A análise nas épocas de amostragens, mostrou diferenças significativas na absorção do nitrogênio, para os tubérculos aos 80 dias; para haste aos 20, 40,80 e 100 dias; para folha aos 20,40 e 80 dias; para a planta inteira aos 20, 40, 80 e aos 100 dias.

A concentração do nutriente nos órgãos, obedeceu à seguinte ordem decrescente: folha, haste e tubérculo. As variações ocorridas entre o início do crescimento até a maturação, na concentração, foram mais pronunciadas nas folhas e nas hastes, uma vez que esses órgãos, à medida que a planta cresce, após a acumulação do nutriente o transloca para o órgão de reserva que é o tubérculo.

\section{FOSFORO}

Os dados de concentração e quantidade extraídas de fósforo pelos cultivares, acham-se na tabela 5 .

A análise de variância global dos dados acima, acusou os seguintes resultados:

\begin{tabular}{lccc} 
Causa de Variação & G.L. & Q.M. & F. \\
\hline Blocos & 3 & 38352,11 & 3,26 \\
Cultivares & 5 & 51423,06 & $4,37^{*}$ \\
Resíduo (A) & 15 & 11771,86 & 1,62 \\
\hline Parcelas & $(23)$ & & \\
Epocas & 4 & 895868,16 & $123,60^{* *}$ \\
Blocos x Epocas & 12 & 6533,00 & 0,90 \\
Cult. x Epocas & 20 & 20097,31 & $2,77^{* *}$ \\
Resíduo (B) & 60 & 7248,19 & 1,00 \\
\hline
\end{tabular}

Total

119

Os cultivares diferiram entre si, ao nível de $5 \%$ de probabilidade, na absorção do fósforo. A interação cultivares $X$ épocas, significativa à $1 \%$, demonstrou que os cultivares tem diferentes exigências com relação às épocas do desenvolvimento. 


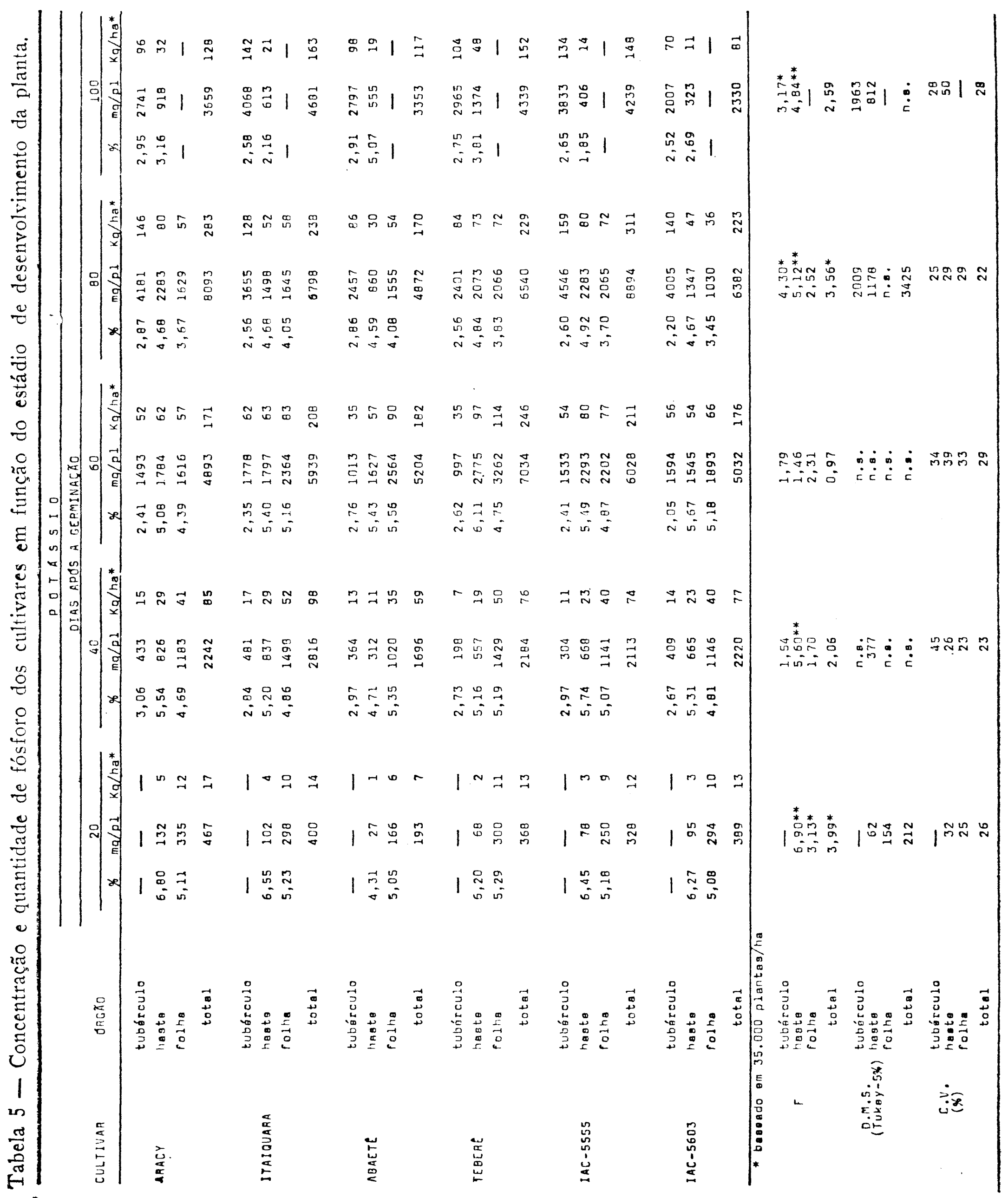


As equações ajustadas para as curvas de absorção acham-se expressas na figura 3 .

O comportamento dos cultivares foi bastante distinto com relação à absorção. O cultivares foi bastante distinto co mrelação à absorção . O cultivar ITAIQUARA apresentou uma absorção crescente do início ao fim do ciclo; ABAETÊ e TEBERÊ absorveram em grande intensidade até aos 60 dias para depois diminuírem a taxa; IAC-5555, ARACY e IAC-5603 o fizeram até aos 80 dias.

O ponto em que os cultivares atingiram o máximo em quantidade absorvida, dados pelas equaçöes ajustadas, foram:

\begin{tabular}{lccc}
\hline Cultivar & $\begin{array}{c}\text { Ponto de } \\
\text { Máximo } \\
\text { (dias) }\end{array}$ & $(\mathrm{mg} /$ planta $)$ & Quantidade Máxima \\
\hline Aracy & 87 & 654 & 23 \\
Itaiquara & 100 & 621 & 22 \\
Abaetê & 81 & 365 & 13 \\
Teberê & 95 & 461 & 16 \\
IAC - 5555 & 88 & 776 & 27 \\
IAC - 5603 & 87 & 507 & 18 \\
\hline
\end{tabular}

Para todos os cultivares, de acordo com os ajustes das equaçôes, não foi observada uma época de exigência máxima. O nutriente foi absorvido durante todo o ciclo da cultura. Assim, recomenda-se que o fertilizante fosfatado seja o mais solúvel possivel e esteja ao alcans? da planta desde o plantio.

Os cultivares extraíram quantidades que vão de 13 a $27 \mathrm{Kg} / \mathrm{ha}$, sendo que a maior parte é exportada pelos tubérculos. Se considerarmos que na aplicação foram colocados perto de $131 \mathrm{Kg} / \mathrm{ha}$ de fósforo (p), veremos que somente de 10 a $20 \%$ do total foi absorvido. A adubação da batatinha portanto fornece uma importante contribuição residual para esse elemento no solo, pois o mesmo é muito pouco lixiviável.

\section{POTÁSSIO}

Os dados referentes à concentração e quantidade de potássio extraída encontram-se na tabela 6 . 


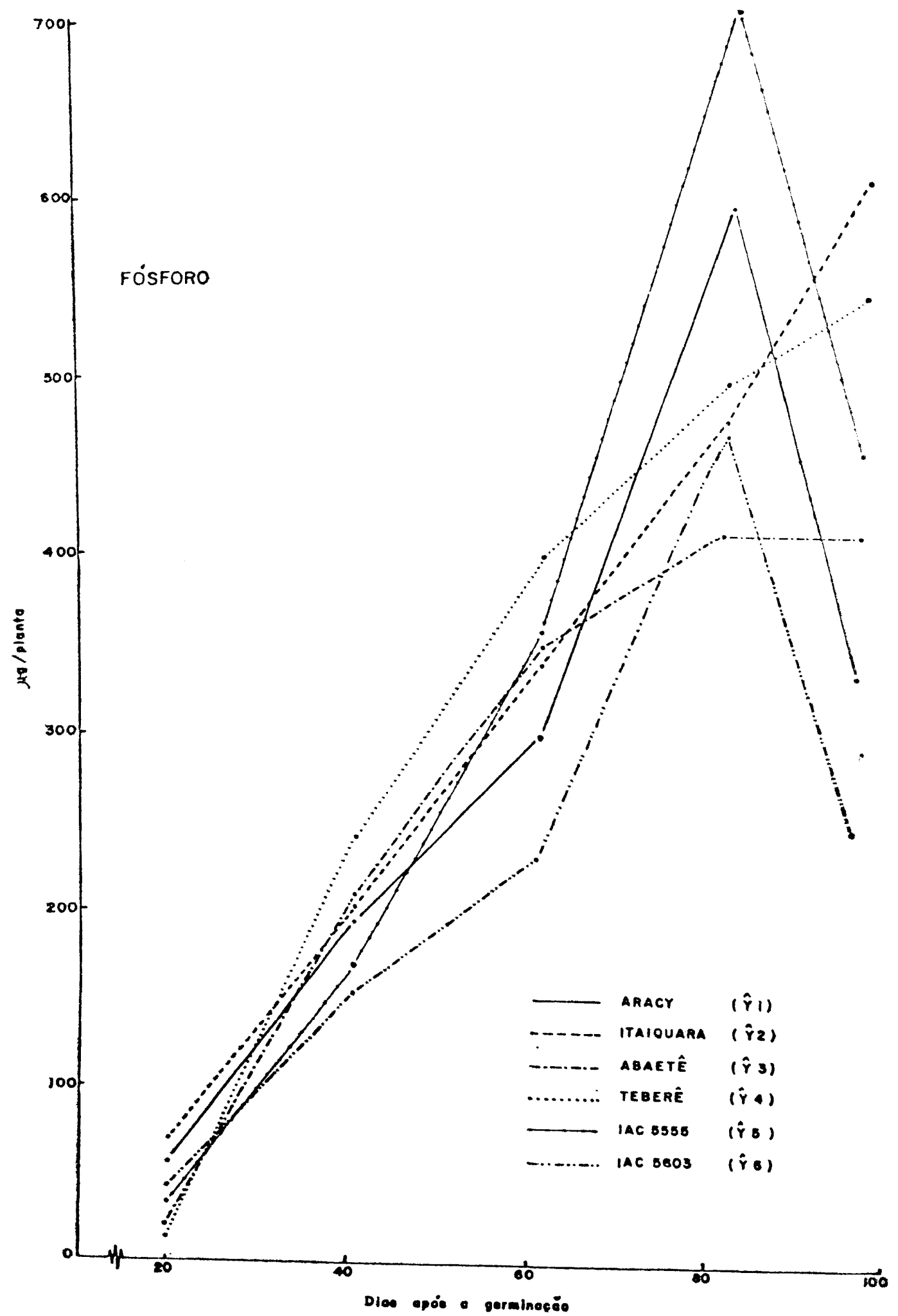

$\eta_{1}=-1350,550+155,351 x-4,289 x^{2}+57,313 \cdot 10^{-3} x^{3}-2 \varepsilon, 257 \cdot 10^{5} x^{4}(x=0,99)$

$i_{2}=-\quad \leq 9,951+\leq, 916 \times(x=0,95)$

$?_{3}^{2}=-294,972+16,059 x-99,114 \cdot 10^{-3} x^{2} \quad\left(r^{2}=0,03\right)$

$\varphi_{\Delta}=-251,062+15,073 x-79,714 \cdot 10^{-2} x^{2} \quad\left(x^{2}=0,06\right)$

$P_{5}=-1089,540+110,084 x-3,603 x^{2}+50,523 \cdot 20^{-3} x^{3}-24,043 \cdot 10^{-5} x^{4}(x \stackrel{2}{0} 0,99)$

$P_{r}=-1182,53 c+117,168 x-3,585 x^{2}+48,690 \cdot 10^{-3} x^{3}-22,117 \cdot 10^{-5} x^{4}(x=0,99)$

Fig. 3 - Curvas representativas da absorção de fósforo em mg/planta (Y) em função da idado $(X)$ dos cultivares. 


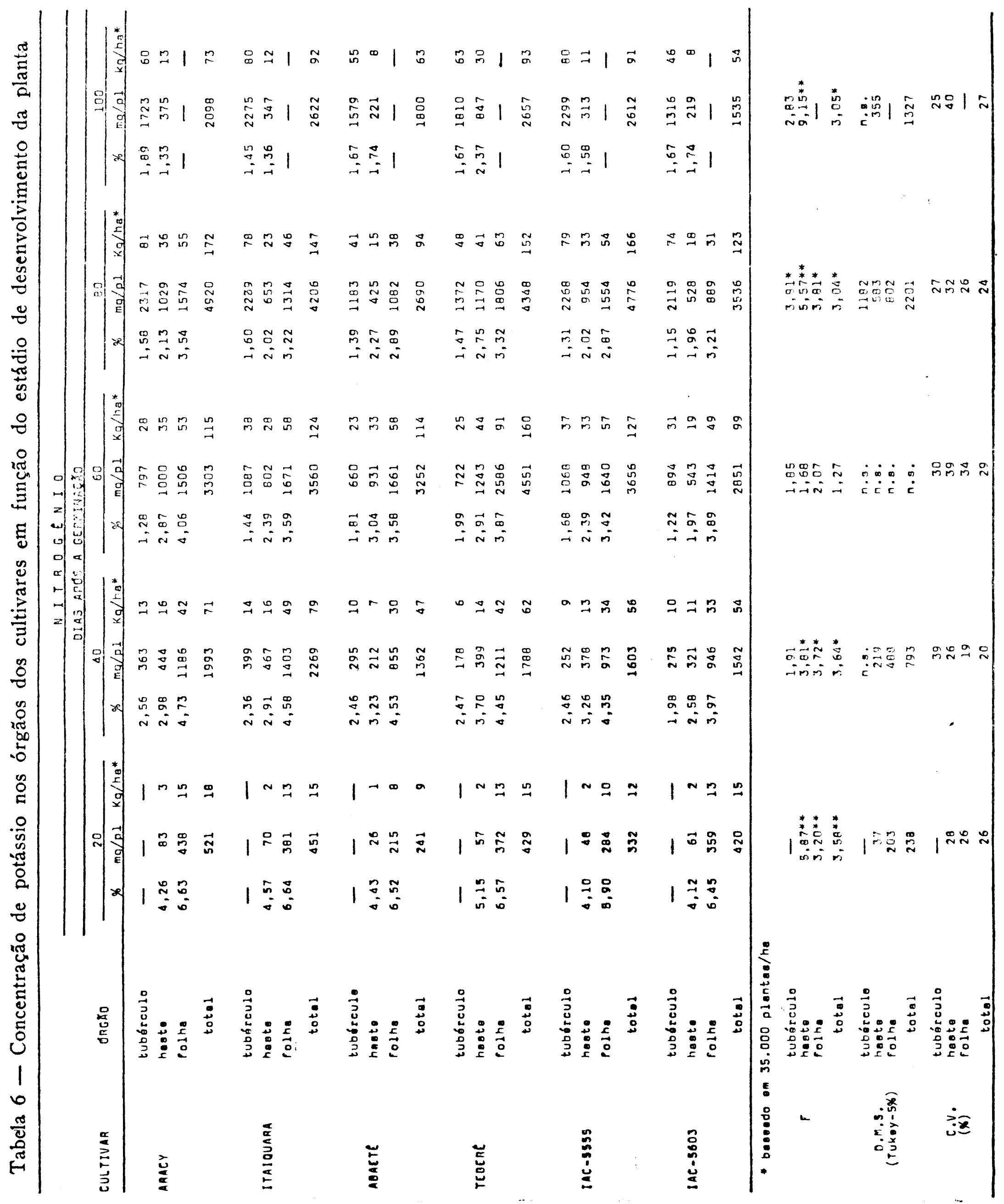


A análise de variância global dos valores acima descritos, resultou no seguinte:

\begin{tabular}{lrrcc}
\hline Cansa de Variação & G.L. & Q.M. & F. \\
\hline Blocos & 3 & 4849897,34 & 3,81 \\
Cultivares & 5 & 5195590,18 & $4,08^{*}$ \\
Resíduo (A) & 14 & 1272569,27 & 1,00 \\
\hline Parcelas & $(23)$ & & & \\
Epocas & 4 & 165779614,56 & $131,41^{* *}$ \\
Blocos x Epocas & 12 & $1011 \quad 168,17$ & 0,80 \\
Cult. x Epocas & 20 & 2215079,50 & $1,76^{*}$ \\
Residuo (B) & 60 & 1261549,81 & 1,00 \\
\hline
\end{tabular}

Total

119

Os cultivares diferiram entre si ao nível de $\overline{\mathbf{5}} \%$ de probabilidade na absorção do potássio. A interação cultivar $\mathrm{x}$ épocas significativa à $5 \%$ revelou uma dependencia entre cultivar e época de absorção.

As equações ajustadas para as curvas de absorção de potássio pelos cultivares encontram-se na figura 4.

Para os cultivares ARACY, ITAIQUARA, IAC-j555 e IAC-5603, ajustaram-se equações de $3 .^{\circ}$ grau, para ABAETÊ de $2 .^{\circ}$ grau e TEBERÊ do $4 .^{\circ}$ grau:

Para todos os cultivares a absorção foi bastante intensa até aos 80 dias, decaindo após esse período.

Os pontos de máxima quantidade acumulada e exigência máxima ajustada foram os seguintes:

\begin{tabular}{lcccc}
\hline Cultivar & $\begin{array}{c}\text { Ponto de } \\
\text { Máximo } \\
\text { (dias) }\end{array}$ & $\begin{array}{c}\text { Quantidade } \\
\end{array}$ & $\begin{array}{c}\text { (g/plantas } \\
(\mathrm{kg} / \mathrm{ha})\end{array}$ & $\begin{array}{c}\text { Ponto de } \\
\text { Inflexão } \\
\text { (dias })\end{array}$ \\
\hline Aracy & 79 & 7603 & 266 & 51 \\
Itaiquara & 79 & 7936 & 243 & 42 \\
Abaetê & 73 & 4794 & 168 & - \\
Teberê & 69 & 7543 & 264 & - \\
IAC - 5555 & 79 & 8708 & 305 & 52 \\
IAC - 5603 & 76 & 6373 & 223 & 48 \\
\hline
\end{tabular}




\section{ENXÔFRE}

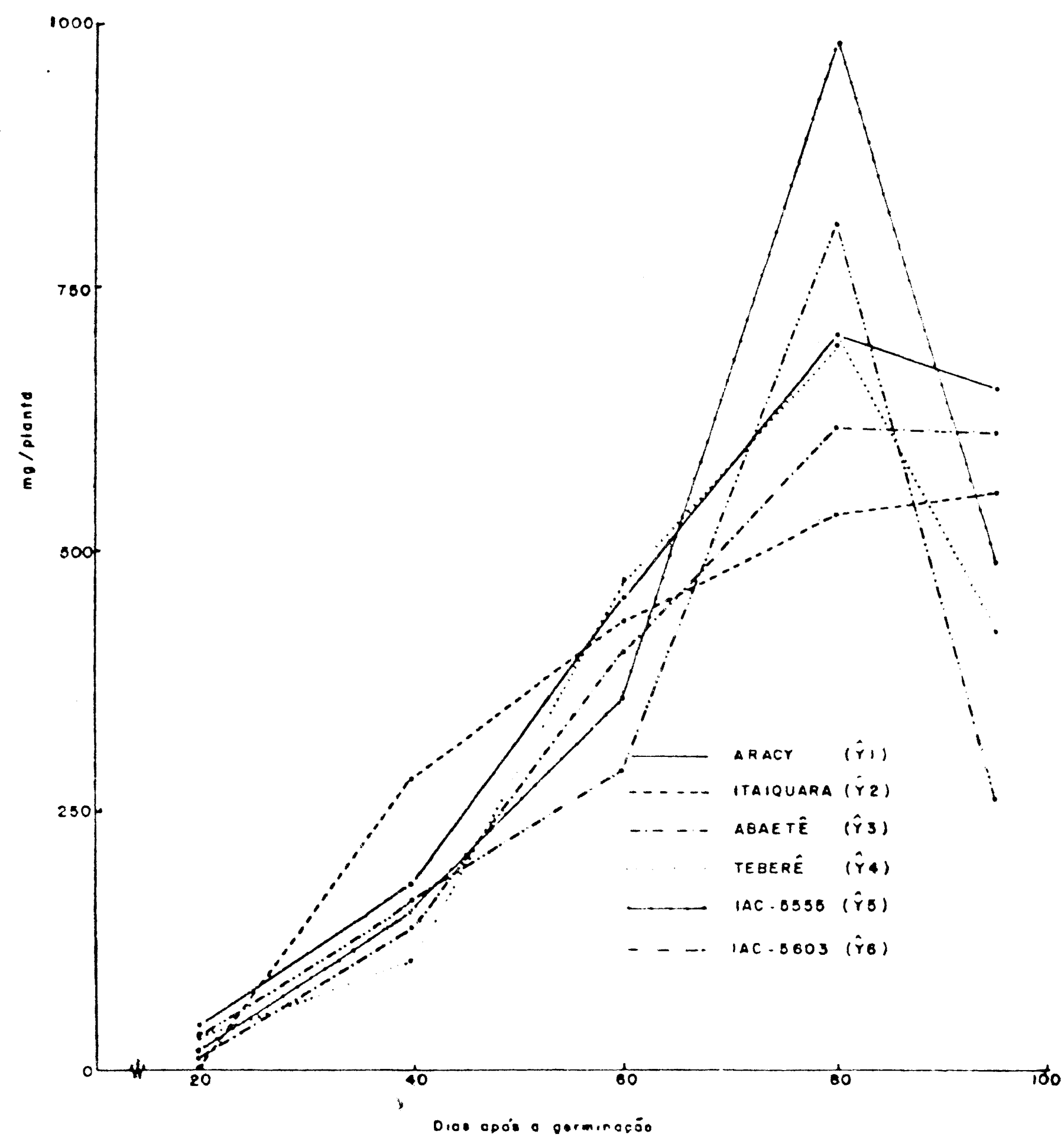

$P_{1}=5620,628-478,781 x+13,052 x^{2}-84,489 \cdot 10^{3} x^{3} \quad(x=0,97)$

$P_{2}=-143,801-56,754 x+4,884 x^{2}-38,376 \cdot 10^{-3} x^{3} \quad\left(x^{2}=0,99\right)$

$P_{3}=-4727,300+259,269 x-1,764 x^{2} \quad(x=0,87)$

$P_{4}=21991,770-2157,465 x+68,577 x^{2}-80,074 \cdot 10^{-2} x^{3}+31,306 \cdot 10^{-4} x^{4}(x=0,99)$

$P_{5}=6485,732-577,482 x+15,607 x^{2}-10,052 \cdot 10^{-2} x^{3} \quad(x=0,99)$

$P_{6}=3181,782-304,086 x+9,606 x^{2}-66,491.10^{-3} x^{3} \quad\left(x^{2}=0,99\right)$

Fig. 4 - Curvas representativas da absorção de potássio em mg/planta ${ }^{\wedge}(Y)$ em função da idade $(X)$ dos cultivares. 
Os cultivares ABAETE e TEBERÊ atingiram o máximc de absorção cerca de 3 a 10 dias antes dos demais, porém o fizeram em menor quantidade.

O período compreendido entre 42 e 52 dias, segundo as equações ajustadas foi aquele cuja taxa de acumulação de potássio foi máxima. Isso, porém não indica necessariamente que o fertilizante deva ser parcelado em duas aplicações. GARGANTINI et alii (1963) também observaram taxas de acumulação elevadas nesse período.

Os autores acima recomendam uma única aplicação por ocasião do plantio, justificando a pouca perda por águas de percolação, do potássio, baseados em trabalho sobre movimento de íons $\mathrm{NO}_{3}^{-}, \mathrm{NH}_{4}{ }^{+}, \mathrm{K}+\mathbf{e}$ $\mathrm{PO}_{4}-$ - no perfil do solo por KUPPER et alii (1973).

Em estudos realizados pelo Instituto Agronômico, Campinas, no Estado de São Paulo, não se observou resposta à adubação com potássio, com exceção de alguns ensaios no Vale do Paraíba (GARGANTINI et alii, 1965), apesar da batatinha o exigir em grande quantidade.

A quantidade de potássio extraída variou entre cultivares de 168 a $305 \mathrm{~kg} / \mathrm{ha}$, dados esses que se encontram dentro dos limites obtidos por outros autores.

A análise das quantidades extraídas nas épocas de amostragens revelou mais significância no início e no fim do ciclo.

A concentração do potássio foi mais alta pela ordem: nas hastes, nas folhas e nos tubérculos.

Aos 40 dias, a concentração do potássio nos diversos órgãos, para efeito de diagnose nutricional por ser o início da época de altas taxas de acumulação, foi a seguinte:

$\begin{array}{ll}\text { Tubérculo } & -\quad 2,67 \text { a } 3,06 \% \\ \text { Haste } & -\quad 4,71 \text { a } 5,74 \% \\ \text { Folha } & -\quad 4,69 \text { a } 5,35 \%\end{array}$

\section{CÁLCIO}

Os dados analíticos da quantidade extraída e concentrada de cálcio, acham-se na tabela 7 .

A nálise de variância global dos dados, apresentou os seguintes resultados: 


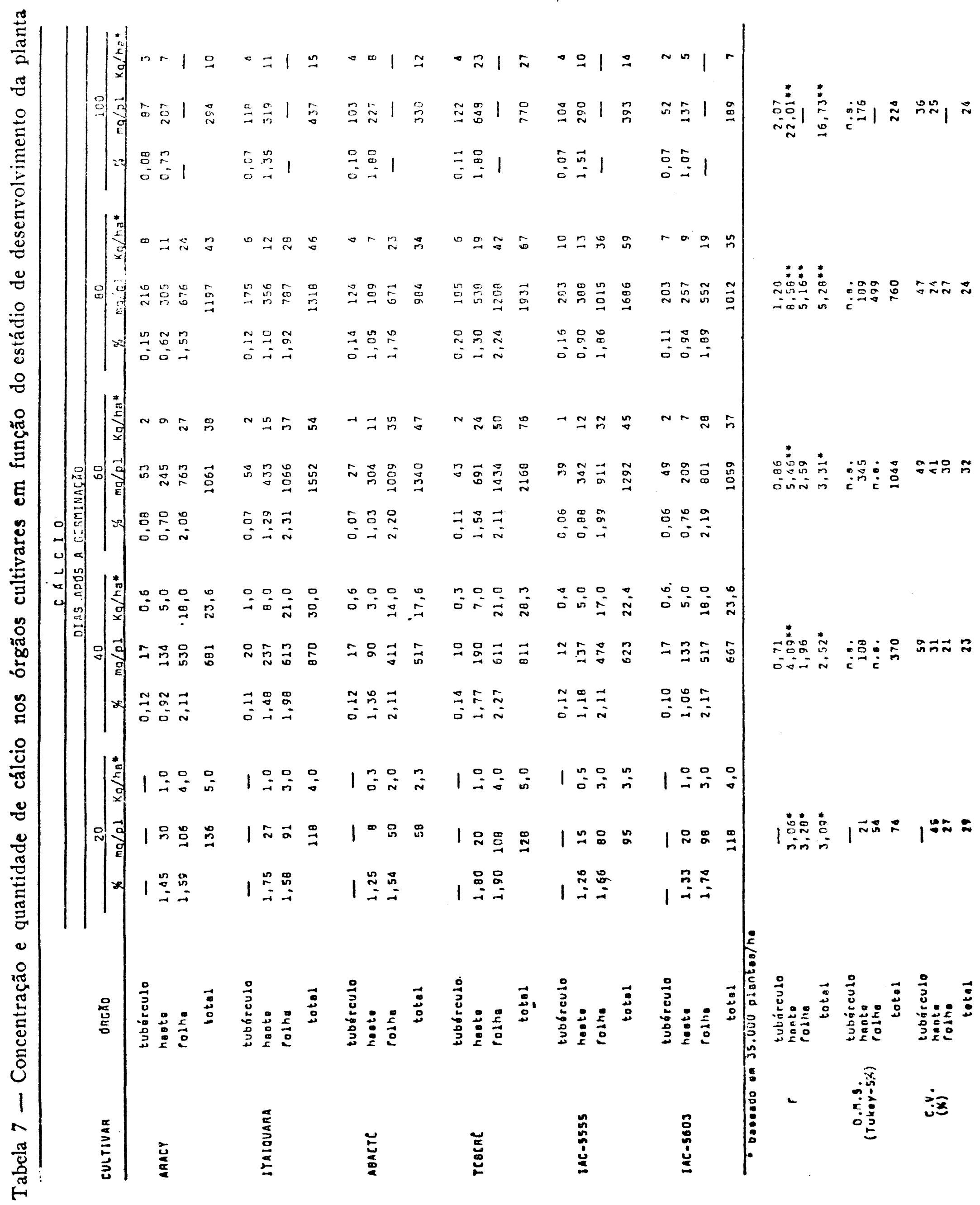




\begin{tabular}{lrrr}
\hline Causa de Variação & G.L. & Q.M. & F. \\
\hline Blocos & 3 & 192980,82 & 2,84 \\
Cultivares & 5 & 842079,95 & 12,40 \\
Resíduo (A) & 15 & 67906,38 & 0,95 \\
\hline Parcelas & $(23)$ & & \\
Epocas & 4 & 7975137,66 & $111,86^{* * *}$ \\
Blocos x Epocas & 12 & 40437,05 & 0,57 \\
Cult. x Epocas & 20 & 163039,34 & $2,29 * *$ \\
Resíduo (B) & 60 & 71295,97 & 1,00
\end{tabular}

Total

Os cultivares diferiram ao nível de $1 \%$ de probabilidade na absorção do cálcio. A interação com épocas também significativa nesse nível, mostrou que os cultivares diferem com relação à época de absorção do cálcio.

As equações ajustadas para as curvas de absorção de cálcio pelos cultivares, acham-se expressas na figura 5. Os ajustes recaíram em equações do $2 .^{\circ}, 3 .^{\circ}$ e $4^{\circ}$ grau, demonstrando distintos aspectos de absorção.

Os pontos relativos à quantidade e épocas de exigência máxima, foram os seguintes:

\begin{tabular}{|c|c|c|c|c|}
\hline \multirow{2}{*}{ Cultivar } & \multirow{2}{*}{$\begin{array}{c}\text { Ponto de } \\
\text { Máximo } \\
\text { (dias) }\end{array}$} & \multicolumn{2}{|c|}{ Quantidade Máxima } & \multirow{2}{*}{$\begin{array}{l}\text { Ponto de } \\
\text { Inflexão } \\
\text { (dias) }\end{array}$} \\
\hline & & (g/plantas & $(\mathrm{kg} / \mathrm{ha})^{*}$ & \\
\hline Aracy & 72 & 1224 & 43 & 39 \\
\hline Itaiquara & 64 & 1466 & 51 & - \\
\hline Abaetê & 65 & 1369 & 48 & - \\
\hline Teberê & 68 & 2288 & 80 & - \\
\hline IAC -5555 & 75 & 1669 & 58 & 48 \\
\hline IAC -5603 & 62 & 1066 & 37 & - \\
\hline
\end{tabular}

O cultivar TEBERE apresentou a extração mais elevada de cálcio, enquanto que o IAC-5603, um dos mais produtivos, o exigiu em menor quantidade. 


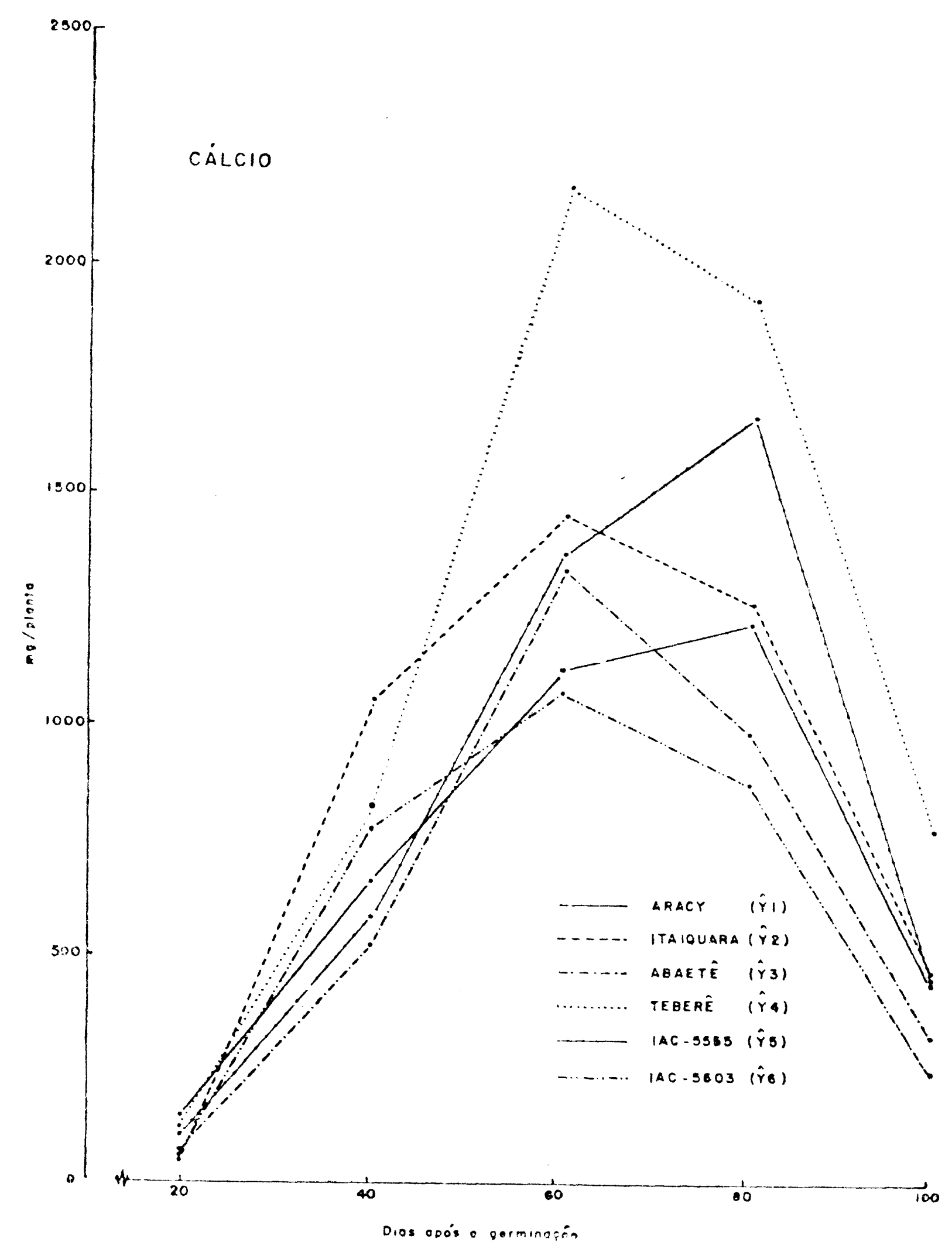

$P_{1}=75,608-14,340 x+1,075 x^{2}-90,887 \cdot 20^{4} x^{3} \quad(x \geq 0,99)$

$P_{2}=-1558,124+95,071 x-74,704 \cdot 10^{-2} x^{2} \quad\left(=\frac{?}{9}, 96\right)$

$P_{3}=3931,209-398,300 x+13,153 x^{2}-15,844 \cdot 10^{-2} x^{3}+63,146 \cdot 10^{-5} x^{4} \quad\left(x^{2}=0,99\right)$

$P_{4}^{3}=5417,419-539,780 x+17,540 x^{2}-20,450 \cdot 10^{-2} x^{3}+70,429 \cdot 10^{-5} x^{4} \quad\left(x^{2}=0,99\right)$

$P_{5}=921,536-87,552 x+2,723 x^{2}-19,044 \cdot 10^{-3} x^{3} \quad\left(x^{2}=0,99\right)$

$P_{6}=-1127,840+70,611 x-56,814 \cdot 10^{2} x^{2} \quad\left(x^{2}=0,95\right)$

Fig. 5 - Curvas representativas da absorção de cálcio em $\mathrm{mg} / \mathrm{planta}^{\wedge}(\mathrm{Y})$ em função da idade $(X)$ dos cultivares. 
As quantidades extraídas de cálcio variam de 3 a $80 \mathrm{~kg} / \mathrm{ha}$. Cêrca de dez por cento (10\%) somente, dessas quantidades foram exportadas pelos tubérculos, demonstrando que muito pouco do cálcio absorvido é translocado para os tubérculos.

O cálcio foi absorvido em quantidades superiores ao fósforo, fato também observado por HAWKINS (1942), CARPENTER (1957) e GARGANTINI et alii (1963) .

O teste de $F$ nas épocas amostradas, mostrou significância para haste e planta inteira em todas as épocas, para folhas aos 20 e 80 dias e para os tubérculos em nenhuma época.

\section{MAGNÉSIO}

Os dados de quantidade e concentração de magnésio, em função da da idade da planta, pelos cultivares, encontram-se na tabela 8 .

A análise de variância global dos dados apresentou os seguintes resultados:

\begin{tabular}{lrrc}
\hline Causa de Variação & G.L. & Q.M. & F. \\
\hline Blocos & 3 & 17876,75 & 1,63 \\
Cultivares & 5 & 58189,21 & $5,29 * *$ \\
Resíduo (A) & 15 & 10998,10 & 1,14 \\
\hline Parcelas & $(23)$ & & \\
Epocas & 4 & 1151407,50 & $119,22 * *$ \\
Blocos x Epocas & 12 & 4797,64 & 0,50 \\
Cult. x Epocas & 20 & 13270,31 & 1,37 \\
Resíduo (B) & 60 & 9657,54 & 1,00 \\
\hline Total & 119 & & \\
\hline
\end{tabular}

Os cultivares diferem ao nível de $1 \%$ de probabilidade, na extração do magnésio. Não houve efeito para interação cultivar x época.

As equações ajustadas para as curvas de absorção de magnésio estão representadas na figura 6 .

Os pontos de máxima quantidade acumulada e exigência máxima foram os seguintes: 


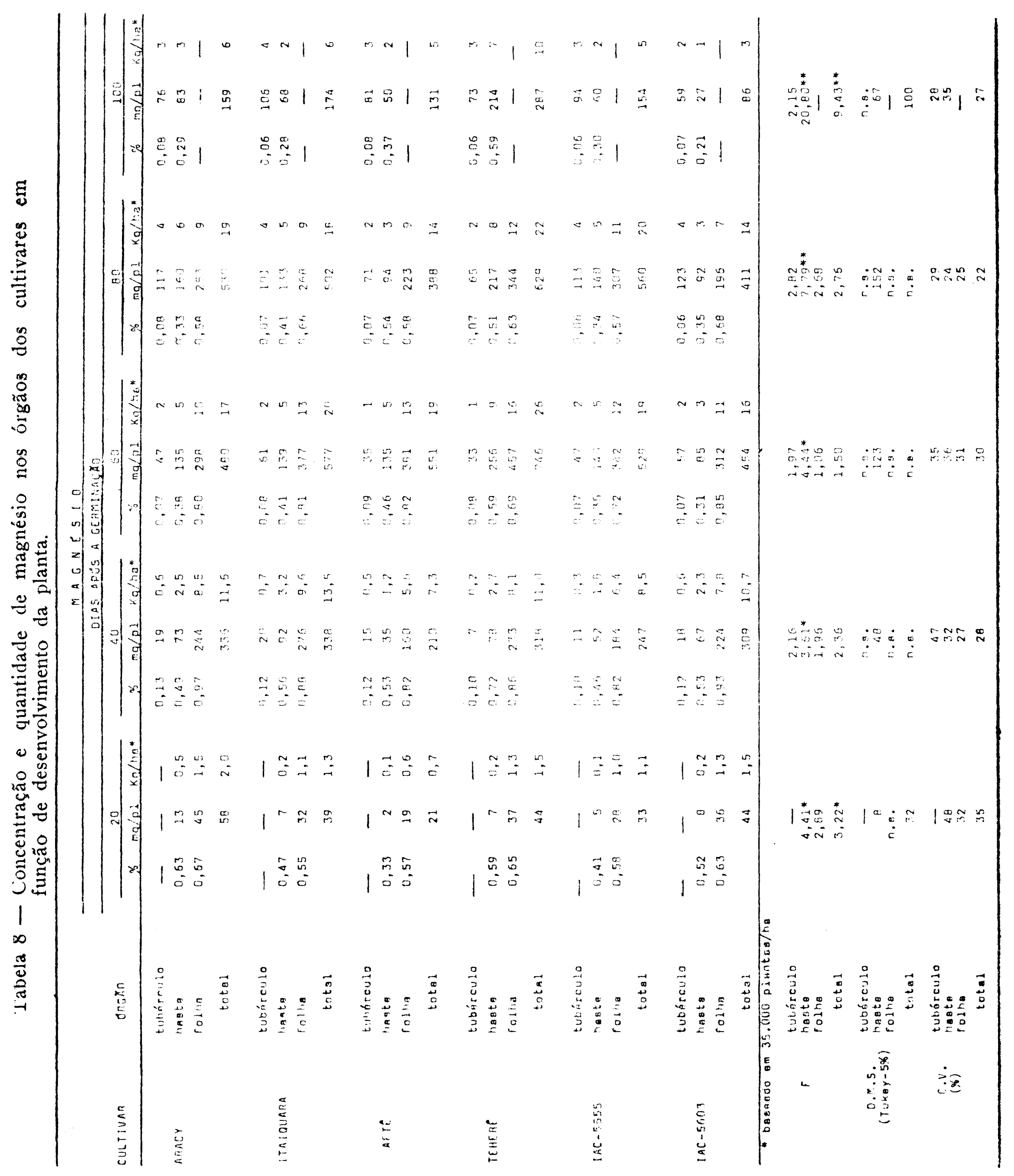




\begin{tabular}{|c|c|c|c|c|}
\hline \multirow{2}{*}{ Cultivar } & \multirow{2}{*}{$\begin{array}{c}\text { Ponto de } \\
\text { Máximo } \\
\text { (dias) }\end{array}$} & \multicolumn{2}{|c|}{ Quantidade Máxima } & \multirow{2}{*}{$\begin{array}{l}\text { Ponto de } \\
\text { Inflexão } \\
\text { (dias) }\end{array}$} \\
\hline & & (g/plantas & $(\mathrm{kg} / \mathrm{ha})^{*}$ & \\
\hline Aracy & 64 & 515 & 18 & - \\
\hline Itaiquara & 63 & 570 & 20 & - \\
\hline Abaetê & 64 & 463 & 16 & - \\
\hline Teberê & 72 & 718 & 25 & 33 \\
\hline $1 \mathrm{AC}-5.555$ & 73 & 589 & 21 & 43 \\
\hline$I A C-5603$ & 62 & 457 & 16 & - \\
\hline
\end{tabular}

Os cultivares TEBERE e IAC-5555 tiveram seu ponto de máximo cêrca de 10 dias mais tarde que os demais e abscrveram quantidades superiores.

As quantidades extraídas de magnésio pelos cultivares variam de a $25 \mathrm{~kg} / \mathrm{ha}$. Somente por volta de vinte por cento $(20 \%)$ do magnésio foi acumulado nos tubérculos. Este resultado foi semelhante ao ocorrido com o cálcio.

A haste foi o órgão que mais apresentou significância nas quantidades extraídas de magnésio.

Como podemos observar pela figura 6 , aos 40 dias aproximadamente os cultivares apresentaram altas taxas de acumulação de magnésio.

\section{ENXOFRE}

As quantidades extraídas e concentradas de enxofre pelos cultivares em função do estádio do desenvolvimento encontram-se na tabela 9 .

\begin{tabular}{lccc}
\hline Causa de Variação & G.L. & Q.M. & F. \\
\hline Blocos & 3 & 22273,92 & 2,32 \\
Cultivares & 5 & 50987,00 & $4,34^{*}$ \\
Residuo (A) & 15 & 11742,41 & 1,20 \\
\hline Parcelas & $(23)$ & & \\
Epocas & 4 & 1608452,59 & $163,72^{* * *}$ \\
Blocos x Épocas & 12 & 12906,85 & 1,31 \\
Cult. x Épocas & 20 & 33934,17 & $3,45^{* *}$ \\
Resíduo (B) & 60 & 9824,46 & 1,00 \\
Total & 119 & &
\end{tabular}




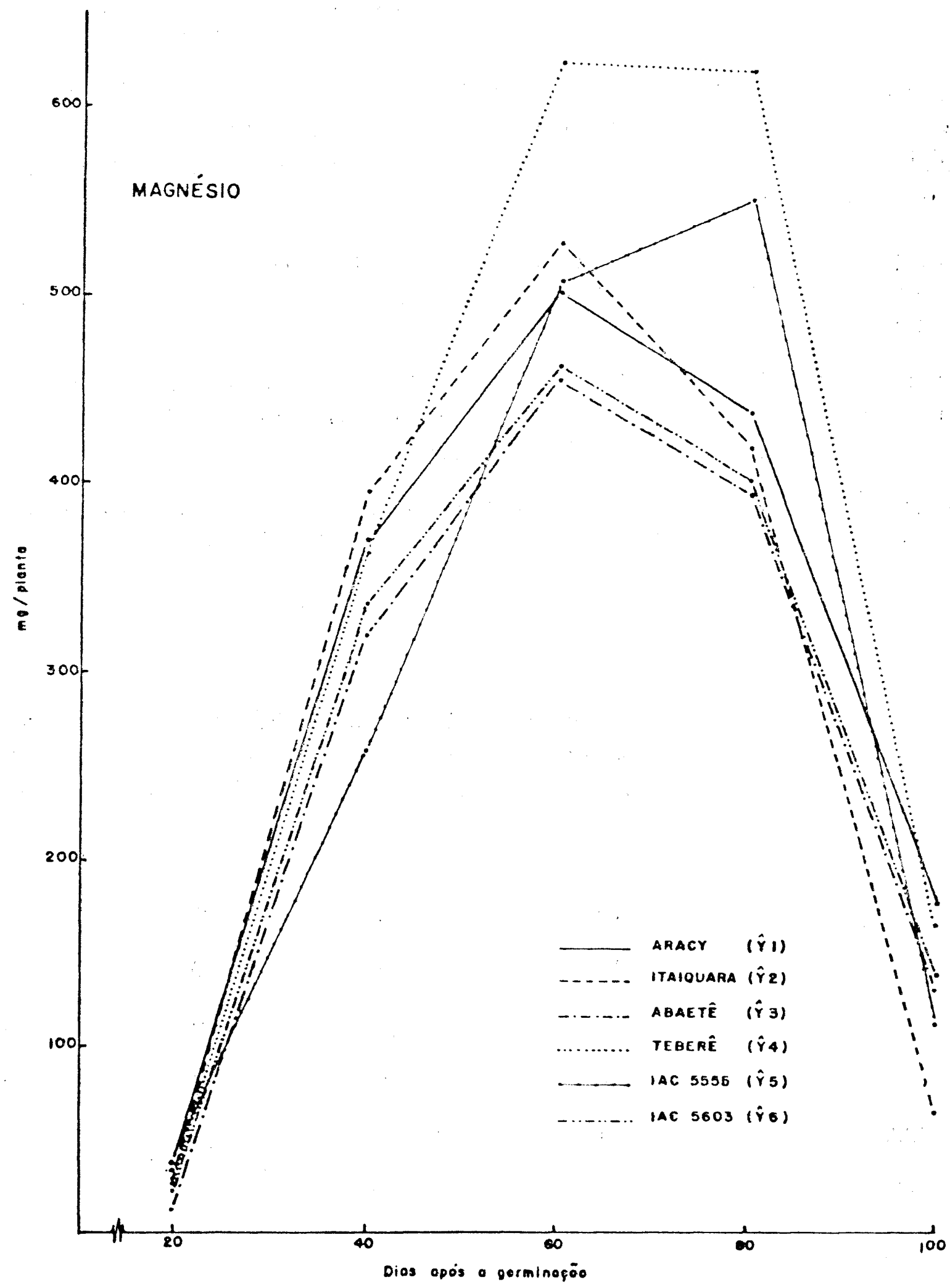

$$
\begin{array}{lc}
P_{1}=-501,376+31,774 x-24,826 \cdot 10^{-2} x^{2} & \left(r^{2}=0,94\right) \\
P_{2}=-588,098+36,604 x-28,906 \cdot 10^{-2} x^{2} & \left(r^{2}=0,99\right) \\
P_{3}=-557,600+31,921 x-24,947 \cdot 10^{-2} x^{2} & \left(r^{2}=0,87\right) \\
P_{4}=-189,442+4,570 x+39,768 \cdot 10^{-2} x^{2}-39,720 \cdot 10^{-4} x^{3}\left(r^{2}=0,95\right) \\
P_{5}=98,664-14,832 x+, 67,867 \cdot 10^{-2} x^{2}-52,508 \cdot 10^{-4} x^{3}\left(r^{2}=0,99\right) \\
P_{6}=-478,574+30,240 x-24,432 \cdot 10^{-2} x^{2} & \left(r^{2}=0,98\right)
\end{array}
$$

Fig. 6 - Curvas representativas da absorção de magnésio em mg/planta $(\hat{Y})$ em função da idade $(X)$ dos cultivares. 
Os cultivares diferiram ao nível de $5 \%$ de probabilidade na extração do enxofre. A interação cultivar $\mathrm{X}$ época, significativa à $1 \%$ de probabilidade, mostrou que existe uma dependência entre cultivar $\mathbf{e}$ época de absorção.

As equações ajustadas para as curvas de absorção de enxofre estão expressas na figura 7 . Os ajustes recaíram sobre equações do 2.0, 3. e $4 .^{\circ}$ graus.

Como podemos observar, se compararmos as curvas de absorção de fósforo e de enxofre verificaremos que o formato das curvas para alguns cultivares é relativamente semelhante.

Os pontos em que se verificaram as máximas quantidades acumuladas e os de exigência máxima foram os seguintes:

\begin{tabular}{lcccc}
\hline Cultivar & $\begin{array}{c}\text { Ponto de } \\
\text { Máximo } \\
(\text { dias })\end{array}$ & Quantidade Máxima & $\begin{array}{c}\text { Ponto de } \\
\text { Inflexão } \\
\text { (dias) }\end{array}$ \\
\hline Aracy & 82 & 575 & 20 & 52 \\
Itaiquara & 91 & 532 & 19 & - \\
Abaetê & 82 & 484 & 17 & 51 \\
Teberê & 82 & 721 & 25 & 54 \\
IAC - 5555 & 88 & 1080 & 38 & - \\
IAC - 5603 & 87 & 879 & 31 & - \\
& & & & \\
\hline
\end{tabular}

As quantidades extraídas variam de 17 a $38 \mathrm{Kg} / \mathrm{ha}$ entre os cultivares, um pouco acima dos valores observados por HAWKINS (1946) e GARGANTINI et alii (1963) . Os cultivares IAC-5555 e IAC-5603 foram os que mais acumularam enxofre.

De uma forma geral os cultivares absorveram continumente o enxofre, com exceção de IAC-5555 e IAC-5603 que apresentaram um pico de máximo bem acentuado aos 80 dias aproximadamente.

O período de maior exigência esteve entre 40 e 60 dias. 


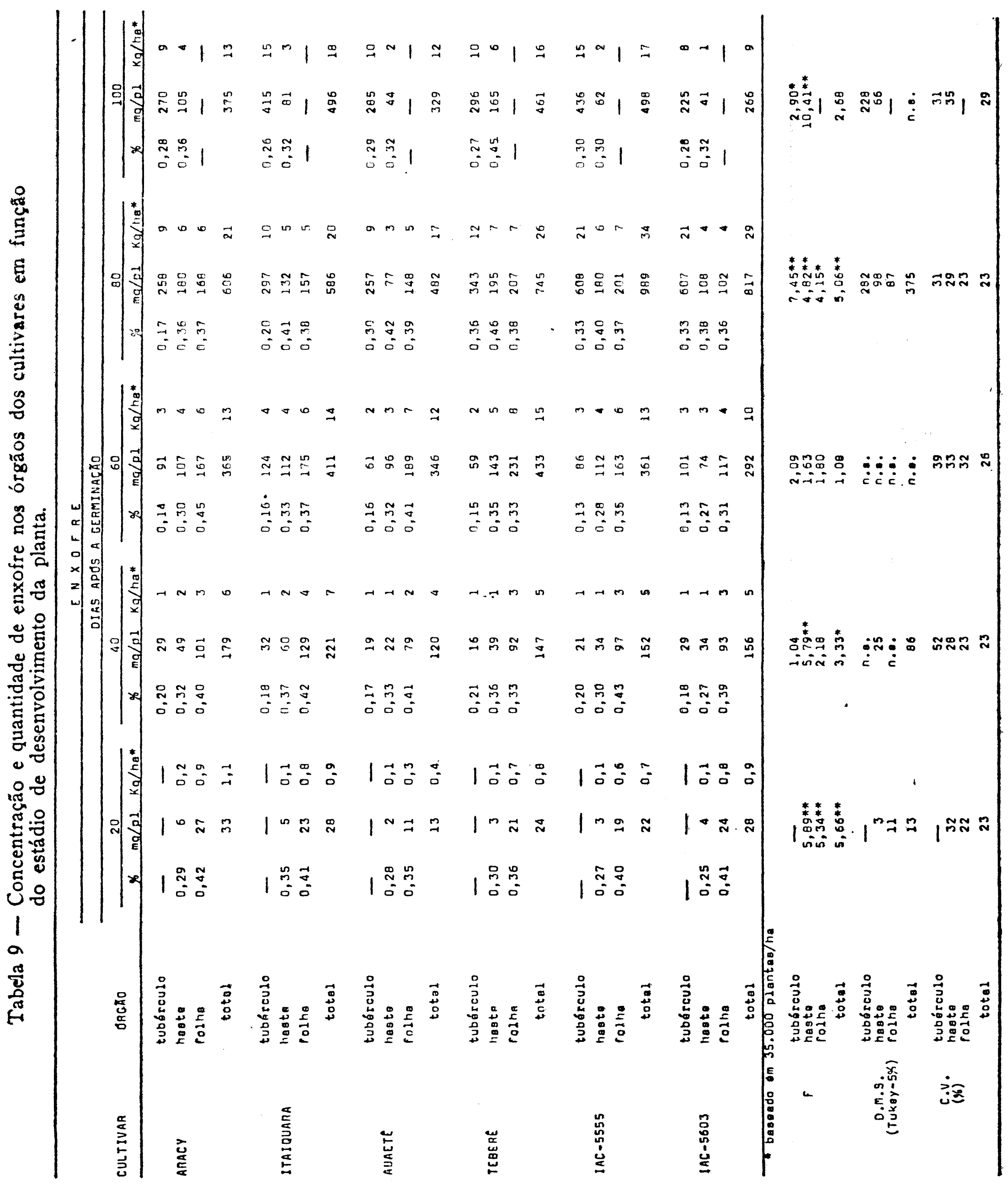




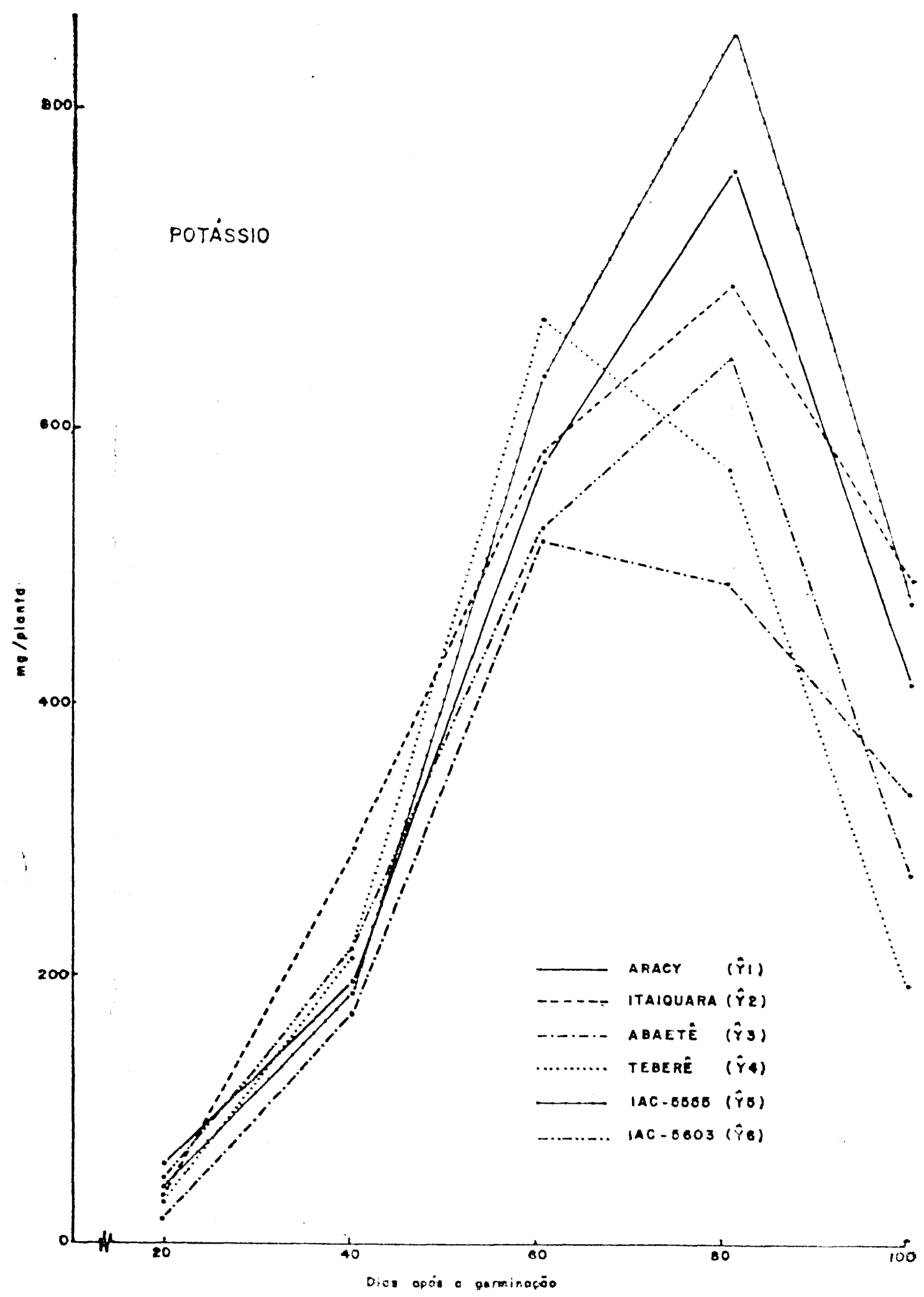

$P_{I}=344,535=29,740 x+83,344 \cdot 10^{-2} x^{2}-53,222 \cdot 10^{-4} x^{3} \quad\left(I^{2}=0,98\right)$

$P_{2}=-331,164+18,903 x-10,345 \cdot 10^{2} x^{2} \quad\left(x^{2}=0,96\right)$

$P_{3}=225,564-22,028 x+65,526 \cdot 10^{-2} x^{2}-42,460 \cdot 10^{-4} x^{3} \quad(r=0,99)$

$P_{4}=591,849-50,583 x+1,286 \quad x^{2}-79,255 \cdot 10^{-4} x^{3} \quad\left(r^{2}=0,99\right)$

$P_{5}=-2238,730+226,700 x-7,590 \quad x^{2}+10,470 \cdot 10^{-2} x^{3}-48,836 \cdot 10^{-5} x^{4}\left(x^{2}=0,99\right)$

$9_{6}=-2330,160+234,061 x-7,703, x^{2}+10,443 \cdot 10^{-2} x^{3}-48,212: 10^{-5} x^{4}(r=0,99)$

Fig. 7 - Curvas representativas da absorção de enxôfre em mg/planta (Y) em função da idade $(X)$ dos cultivares. 


\section{MICRONUTRIENTES BORO}

As análises referentes à concentração e extração de boro, pelos cultivares, foram realizadas apenas para uma época de amostragem.

A época escolhida foi a mais próxima do máximo de acumulação para todos os outros elementos, aos 80 dias.

Os dados referentes a quantidade e concentração de boro no tubérculo, haste e folha dos cultivares acham-se na tabela 10 .

$\mathrm{O}$ teste de $\mathrm{F}$ mostrou haver significância apenas para as quantidades extraídas pelos tubérculos, ao nível de 5\% de probabilidade.

O cultivar IAC-5603 foi o que mais acumulou boro nos tubérculos, embora quando consideramos o total pela planta tenha sido ARACY.

A concentração do elemento na folha esteve entre 37,9 e $44,9 \mathrm{ppm}$, faixa essa considerada, de acordo com HIROGE et alii (1971) .

COBRE

Os resultados de quantidades extraídas e concentradas de cobre, nas diversas partes da planta, acham-se expressos na tabela 11 .

A análise de variância global para os resultados citados anteriormente foi a seguinte:

\begin{tabular}{lccc}
\hline Causa de Variação & G.L. & Q.M. & F. \\
\hline Blocos & 3 & 0,0701 & $4,50^{*}$ \\
Cultivares & 5 & 0,0620 & $3,98^{*}$ \\
Resíduo (A) & 15 & 0,0155 & 1,16 \\
\hline Parcelas & $(23)$ & & \\
Epocas & 4 & 0,9972 & $74,44^{* *}$ \\
Blocos x Epocas & 12 & 0,0161 & 1,20 \\
Cult. x Epocas & 20 & 0,0195 & 1,46 \\
Resíduo (B) & 60 & 0,0133 & 1,00 \\
\hline
\end{tabular}

Total

119

Tabela 10 - Concentração e quantidade de boro nos órgãos dos cultivares aos 80 dias após a germinação.

\begin{tabular}{|c|c|c|c|c|c|c|c|c|c|c|c|}
\hline \multirow[b]{2}{*}{ EULTIAR } & \multicolumn{9}{|c|}{$\theta \times 0 \times 0$} & \multirow{2}{*}{\multicolumn{2}{|c|}{ TOTAL }} \\
\hline & \multicolumn{3}{|c|}{ TUBERCULO } & & \multicolumn{3}{|c|}{ FQLHA } & & \\
\hline amacr & 12,8 & 1950 & 69 & 25,0 & 1220 & 43 & 44,6 & 1970 & 69 & 5140 & 180 \\
\hline ITALOMARA & 9,6 & 1370 & 47 & 41,1 & 1300 & 46 & 38,9 & 1600 & 56 & 4278 & 149 \\
\hline abatte & 10,3 & 950 & 33 & 29,9 & 520 & 18 & 37,9 & 1458 & 51 & 2920 & 102 \\
\hline Tresent. & 9,3 & 850 & 30 & 24,2 & 1020 & 36 & 44,4 & 2428 & 15 & 4298 & 150 \\
\hline I:AC -5555 & 6,7 & 1110 & 39 & 26,9 & 1120 & 39 & 39,9 & 2120 & 74 & 4350 & 152 \\
\hline IAC -5603 & 11,7 & 2150 & 72 & 31,5 & 950 & 33 & 44,9 & 1250 & 14 & 4350 & 152 \\
\hline \multicolumn{12}{|c|}{ - vasnado em 35.0no plantas/tre } \\
\hline r & \multicolumn{3}{|c|}{$3,33^{*}$} & \multicolumn{3}{|c|}{ m.s. } & \multicolumn{3}{|c|}{ n.s. } & \multicolumn{2}{|l|}{ n.s. } \\
\hline $\begin{array}{l}\text { D.m.s. } \\
\text { (itukey-sm) }\end{array}$ & \multicolumn{3}{|c|}{1350} & \multicolumn{3}{|c|}{ n.s. } & \multicolumn{3}{|c|}{ n.s. } & \multicolumn{2}{|l|}{ n.e. } \\
\hline $\begin{array}{l}\varepsilon \cdot \bar{v} \\
(\dot{x})\end{array}$ & \multicolumn{3}{|c|}{43} & \multicolumn{3}{|c|}{39} & \multicolumn{3}{|c|}{36} & \multicolumn{2}{|c|}{29} \\
\hline
\end{tabular}




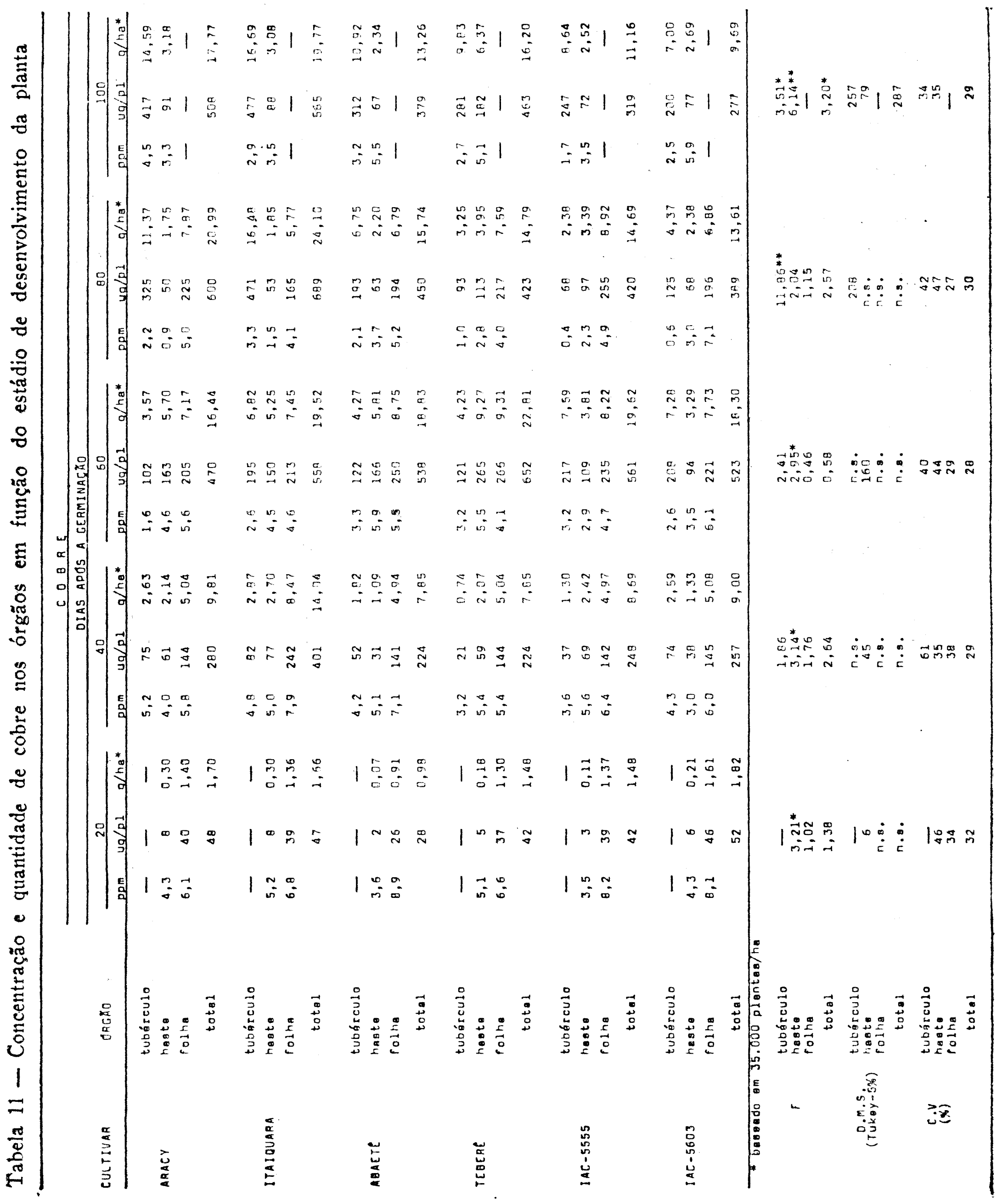


Os cultivares diferiram ao nível de $5 \%$ de probabilidade extração do cobre. A interação cultivar x época não foi significativa, acusando um comportamento semelhante para os cultivares quanto à época de absorção. Esse fenômeno pode ser observado pelo formato semelhante das curvas de absorção representadas na figura 8 .

$\mathrm{Na}$ mesma figura encontram-se as equações ajustadas 1 para as curvas de absorção do cobre. Todos os cultivares se ajustaram à equações do $2 .^{\circ}$ grau.

Os pontos de máxima quantidade extraída foram:

\begin{tabular}{lccc}
\hline Cultivar & $\begin{array}{c}\text { Ponto de } \\
\text { Máximo } \\
\text { (dias) }\end{array}$ & $\mu \mathrm{g} /$ planta & $\mathrm{g} / \mathrm{ha}$ \\
\hline Aracy & 84 & 559 & 20 \\
Itaiquara & 79 & 656 & 23 \\
Abaetê & 74 & 491 & 17 \\
Teberê & 75 & 537 & 19 \\
IAC - 5555 & 70 & 489 & 17 \\
IAC - 5603 & 68 & 461 & 16 \\
\hline
\end{tabular}

As quantidades extraídas de cobre variaram entre os cultivares de 16 a $23 \mathrm{~g} / \mathrm{ha}$; quantidades bem menores do que as apresentadas por KUPERS (1975) .

O cultivar ITAIQUARA foi o de maior conteúdo em cobre e o IAC-5603 o mais precoce em atingir o ponto de máxima acumulação. .

1 - Os dados fornecidos pelas equações foram calculados e estão representados nas mesmas em $\mathrm{mg} /$ planta. Nas tabelas e figuras os dados encontram-se em $\mu /$ planta. para maior facilidade de exposição.

\section{FERRO}

Os dados referentes às quantidades e concentrações encontradas nos diversos cultivares acham-se na tabela 12 .

A análise de variância global dos dados citados anteriormente foi a seguinte: 


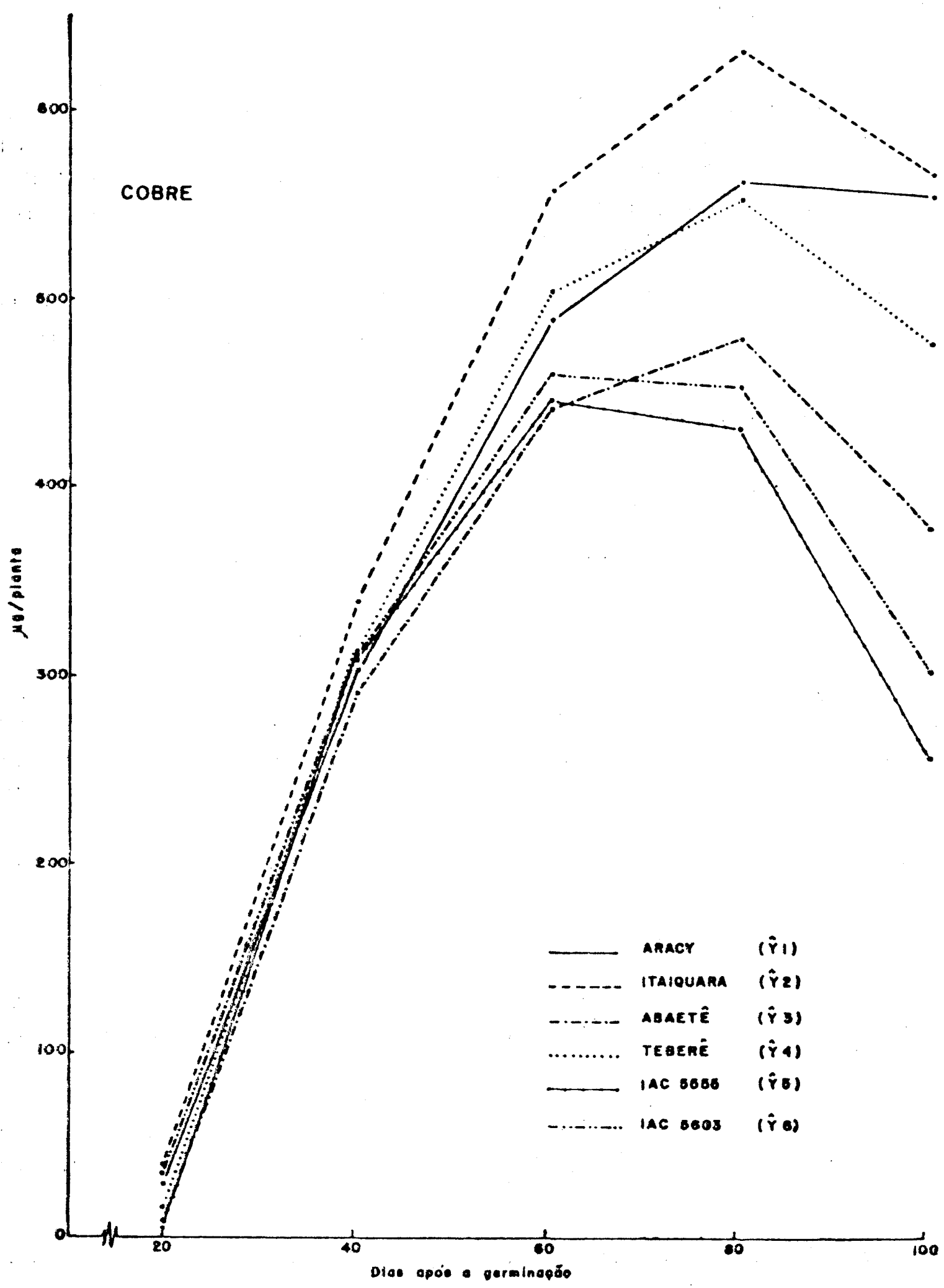

$$
\begin{aligned}
& Q_{1}=-0,345+2,146 \cdot 10^{-2} x-12,721 \cdot 10^{5} x^{2} \quad(= \pm 0,08) \\
& P_{2}=-0,435+2,758 \cdot 10^{2} x-17,553 \cdot 10^{-5} x^{2} \quad(=2=0,99) \\
& 9_{3}=-0,422+2,475 \cdot 10^{-2} x-16,755 \cdot 10^{-5} x^{2} \quad(I=0,92) \\
& P_{4}=-0,421+2,541 \cdot 10^{-2} x-16,849 \cdot 10^{-5} x^{2} \quad(r \stackrel{2}{=} 0,88) \\
& q_{5}=-0,432+2,651 \cdot 10^{2} x-19,074 \cdot 10^{5} x^{2} \quad(I=0,89) \\
& P_{6}=-0,393+2,519 \cdot 10^{-2} x-18,567 \cdot 10^{-5} x^{2} \quad\left(r^{2}=0,91\right)
\end{aligned}
$$

Fig. 8 - Curvas representativas da absorção de cobre em $\mu \mathrm{g} /$ planta $(\hat{\mathbf{Y}})$ em função da idade $(\mathrm{X})$ dos cultivares. 


\begin{tabular}{lccc}
\hline Causa de Variação & G.L. & Q.M. & F. \\
\hline Blocos & 3 & 467,85 & 2,11 \\
Cultivares & 5 & 1130,48 & $5,09^{* *}$ \\
Residuo (A) & 15 & 221,91 & 1,15 \\
Parcelas & $(23)$ & & \\
Epocas & 4 & 21451,92 & $110,85^{* *}$ \\
Blocos x Épocas & 12 & 293,30 & 1,52 \\
Cult. x Epocas & 20 & 401,64 & $2,08^{*}$ \\
Residuo (B) & 60 & 193,52 & 1,00 \\
\end{tabular}

Total

Os cultivares extraíram ferro significativamente diferente ao nível de $1 \%$ de probabilidade. A época de absorção em interação com os cultivares também foi significativa, porém ao nível de $5 \%$.

As equações ajustadas 2 para as curvas de absorção, acham-se na figura 9. Os ajustes recaíram sobre equações de $3 .^{\circ}$ e $4 .^{\circ}$ grau .

Os pontos de máxima acumulação e exigência foram os seguintes:

\begin{tabular}{|c|c|c|c|c|}
\hline \multirow{2}{*}{ Cultivar } & \multirow{2}{*}{$\begin{array}{l}\text { Ponto de } \\
\text { Máximo } \\
\text { (dias) }\end{array}$} & \multicolumn{2}{|c|}{ Quantidade Máxima } & \multirow{2}{*}{$\begin{array}{c}\text { Ponto de } \\
\text { Inflexão } \\
\text { (dias) }\end{array}$} \\
\hline & & $\mu \mathrm{g} /$ planta & $\mathrm{g} / \mathrm{ha}$ & \\
\hline Aracy & 78 & 64815 & 2269 & 48 \\
\hline Itaiquara & 65 & 80645 & 2823 & - \\
\hline Abaetê & 67 & 77392 & 2709 & - \\
\hline T'eberê & 67 & 102487 & 3587 & - \\
\hline $\mathrm{IAC}-5555$ & 76 & 96318 & 3371 & 48 \\
\hline $\mathrm{IAC}-5603$ & 76 & 56414 & 1974 & 49 \\
\hline
\end{tabular}

2 - Os dados fornecidos pelas equações foram calculados e estão representados nas mesmas em $\mathrm{mg} /$ planta. Nas tabelas e figuras os dados encontram-se em $\mu \mathrm{g} /$ planta para maior facilidade de exposição. 


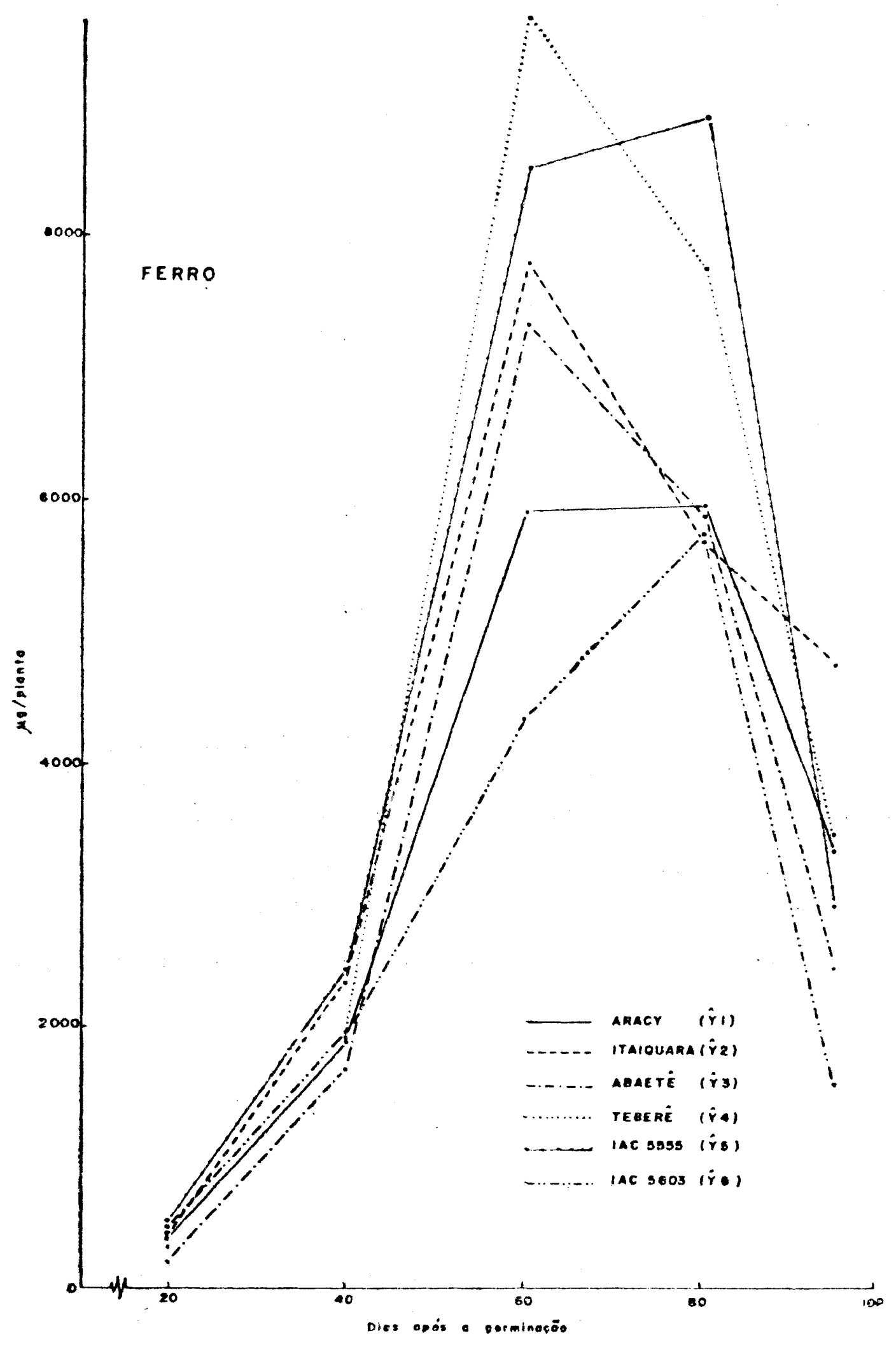

$P_{1}=21,932-2,392 x+82,860 \cdot 10^{-3} x^{2}-57,875 \cdot 10^{-5} x^{3} \quad(=20,96)$

$P_{2}=341,810-33,799 x+1,096 x^{2}-13,160 \cdot 10^{-3} x^{2}+53,856 \cdot 10^{-6} x^{4} \quad\left(x^{2}=0,99\right)$

$P_{3}=315,910-30,750 x+c, 960 x^{2}-11,226 \cdot 10^{-3} x^{3}+44,099 \cdot 10^{-6} x^{4} \quad\left(r^{2}=0,99\right)$

$?_{4}=446,079-43,026 x+1,321 x^{2}-15,512 \cdot 10^{-3} x^{3}+60,859 \cdot 10^{-6} x^{4} \quad(r=0,99)$

$\varphi_{5}^{4}=51,075-5,113 x+15,820 \cdot 10^{-2} x^{2}-10,933 \cdot 10^{-4} x^{2} \quad\left(x^{2}=0,98\right)$

$P_{6}^{\prime}=38,788-3,425 x+00,232 \cdot 10^{-2} x^{2}-67,250 \cdot 10^{-5} x^{3} \quad\left(x^{2}=0,99\right)$

Fig. 9 - Curvas representativas da absorção de ferro em $\mu \mathrm{g} /$ planta $(\hat{\mathrm{Y}})$ em função da idade $(\mathrm{X})$ dos cultivares. 
As quantidades extraídas de ferro pelos cultivares estiveram entre o intervalo de 1974 a $3587 \mathrm{~g} / \mathrm{ha}$. Com exceção de dados sobre a concentração do ferro nos tubérculos, a literatura acha-se em omissão sobre referências de extração deste micronutrientes pela batatinha.

\section{EXPORTAÇÃO DE NUTRIENTES}

As quantidades exportadas de nitrogênio, fósforo, potássio, cálcio, magnésio, enxofre, cobre e ferro através dos tubérculos, pelos cultivares, encontram-se na tabela 13 .

Calculamos as quantidades exportadas de nutrientes pelos tubérculos baseados na época (dias após a germinação) mais próxima da produção máxima de matéria fresca. Os pontos e as quantidades máximas de matéria fresca foram estimados a partir de equações de regressão ajustadas, expostos a seguir:

\begin{tabular}{lccc}
\hline Cultivar & $\begin{array}{c}\text { Ponto de } \\
\text { Máximo } \\
\text { (dias) }\end{array}$ & Equação Ajustada & $\begin{array}{c}\text { Coeficiente } \\
\text { de } \\
\text { Determi- } \\
\text { nação }\end{array}$ \\
\hline Aracy & 85 & $\mathrm{Y}=-0,3142 \mathrm{x}^{2}+53,42 \mathrm{x}-1701,25$ & $\mathrm{r}^{2}=0,98$ \\
Itaiquara & 100 & $\mathrm{Y}=14,3703 \mathrm{x}-366,50$ & $\mathrm{r}^{2}=0,94$ \\
Abaetê & 100 & $\mathrm{Y}=7,9687 \mathrm{x}-187,03$ & $\mathrm{r}^{2}=0,95$ \\
Teberê & 100 & $\mathrm{Y}=11,0421 \mathrm{x}-326,50$ & $\mathrm{r}^{2}=0,98$ \\
IAC-5555 & 80 & $\mathrm{Y}=-0,3435 \mathrm{x}^{2}+61,33 \mathrm{x}-2031,84$ & $\mathrm{r}^{2}=0,96$ \\
IAC-5603 & 78 & $\mathrm{Y}=-0,6181 \mathrm{x}^{2}+95,92 \mathrm{x}-3049,13$ & $\mathrm{r}^{2}=0,92$
\end{tabular}

Procedemos dessa forma uma vez que a análise conjunta para a concentração dos nutrientes aos 80 e 100 dias apresentou para todos os elementos uma interação significativa entre variedade e época. Portanto as quantidades exportadas foram função da capacidade produtiva dos cultivares.

Os cultivares apresentaram os seguintes intervalos de variação na exportação dos nutrientes através dos tubérculos: 
Tabela 13 - Exportação de nutrientes através dos tubérculos pelos cultivares de batatinha.

\begin{tabular}{|c|c|c|c|c|c|c|c|c|}
\hline \multirow{2}{*}{ Cultivar } & \multicolumn{8}{|c|}{$N U T R I E N T E S$} \\
\hline & $\mathrm{N}$ & $\mathrm{P}$ & $\mathrm{K}$ & $\mathrm{Ca}$ & $\mathrm{Mg}$ & $\mathrm{S}$ & $\mathrm{Cu}$ & $\mathrm{Fe}$ \\
\hline & \multicolumn{6}{|c|}{$(\mathrm{kg} / \mathrm{ha})^{*}$} & \multicolumn{2}{|c|}{$(\mathrm{g} / \mathrm{ha})^{*}$} \\
\hline Aracy & 81 & 15 & 146 & 7,5 & 4,0 & 9 & 11 & 598 \\
\hline Itaiquara & 80 & 18 & 142 & 4,1 & 3,7 & 15 & 17 & 1121 \\
\hline Abaetê & 55 & 10 & 98 & 3,6 & 2,8 & 10 & 11 & 381 \\
\hline Teberê & 63 & 12 & 104 & 4,2 & 2,5 & 10 & 10 & 273 \\
\hline IAC- 5555 & 80 & 17 & 159 & 9.9 & 3,9 & 21 & 2 & 633 \\
\hline IAC -5603 & 74 & 12 & 140 & 7,1 & 4,3 & 21 & 4 & 797 \\
\hline
\end{tabular}

* Bascado em 35000 plantas/ha.

\begin{tabular}{ccc}
\hline \multicolumn{2}{l}{ ELEMENTO } & \multicolumn{2}{c}{$\begin{array}{c}\text { Quantidades } \\
\text { Exportadas }\end{array}$} \\
\hline MACRONUTRIENTES & $(\mathbf{k g} / \mathrm{ha})^{*}$ \\
\hline Nitrogênio & $(\mathrm{N})$ & $55-81$ \\
Fósforo & $(\mathrm{P})$ & $10-18$ \\
Potássio & $(\mathrm{K})$ & $98-159$ \\
Cálcio & $(\mathrm{Ca})$ & $3.6-9,9$ \\
Magnésio & $(\mathrm{Mg})$ & $2,5-4.3$ \\
Enxofre & $(\mathrm{S})$ & $9-21$ \\
\hline MICRONUTRIENTES & $(\mathrm{Cu})$ & $(\mathrm{g} / \mathrm{ha})^{*}$ \\
Cobre & $(\mathrm{Fe})$ & $2-17$ \\
Ferro & $273-1121$ \\
\hline
\end{tabular}

* Baseado em 35000 plantas/ha.

\section{PRODUÇÃO DE TUBÉRCULOS}

Os dados referentes à produção de tubérculos pelos cultivares, nos diferentes estádios do desenvolvimento, encontram se na tabela 14.

$\mathrm{O}$ teste $\mathrm{F}$ mostrou que os cultivares diferem entre si na produção de tubérculos, aos 40,60 e 80 dias após a germinação, a 1, 5 e $1 \%$ de probabilidade, respectivamente. Aos 100 dias não houve signifiç̧ncia à $5 \%$, porém o valor obtido para $F=2,60$, está entre 10 e $5 \%$ de signi- 
ficância, cujos valores em tabela são 2,27 e 2,90, respectivamente. Com o exposto, queremos enfatizar, que embora usualmente se utilize niveis até $5 \%$ de probabilidade, os valores estão bem próximos e representam um grau de significância.

Ao cbservar a tabela 14 podemos verificar as altas taxas de acumulaçã de matéria fresca dos tubérculos - Dp. Dos 40 aos 60 dias os cultivares chegam a produzir de 387 a $904 \mathrm{Kg} / \mathrm{ha} /$ dia de matéria fresca. Dos 60 aos 80 dias as taxas variam de 314 a $786 \mathrm{~kg} / \mathrm{ha} /$ dia, época em que os tubérculos crescem mais em tamanho, pois a planta já completou praticamente a tuberização.

Tabela 14 - Produção de matéria fresca nos tubérculos em função da idade da planta.

\begin{tabular}{|c|c|c|c|c|c|c|c|c|c|c|c|}
\hline \multirow{3}{*}{ CULTIVAR } & \multicolumn{11}{|c|}{ Días após a germinaçāo } \\
\hline & \multicolumn{3}{|c|}{40} & \multicolumn{3}{|c|}{60} & \multicolumn{3}{|c|}{80} & \multicolumn{2}{|c|}{100} \\
\hline & $(g / p)\}$ & $\left(K_{g}\right)$ & (ha) * & $(g / p)$ & $(\mathrm{Kg} / \mathrm{r}$ & ha) * & $(g / p)$ & $(\mathrm{Kg} /)$ & ha) * & $(g / p)$ & $\left(K_{g} / h_{g}\right) *$ \\
\hline ARACY & 102,44 & 3 & 505 & 497,34 & 17 & 428 & 753,50 & 26 & 373 & 646,25 & 22619 \\
\hline ITAIDUARA & 127,63 & 4 & 467 & 579.06 & 20 & 267 & 858,50 & 30 & 048 & 992,50 & 34738 \\
\hline ABAETE & 94,81 & 3 & 318 & 321,31 & 11 & 246 & 500,75 & 17 & 526 & 566,25 & $19 \quad 819$ \\
\hline TEBERE & $-58,88$ & 2 & 061 & 347,19 & 12 & 152 & 583,00 & 20 & 405 & 716,25 & 25069 \\
\hline$I A C-5555$ & 75,38 & 2 & 638 & 491,56 & 17 & 205 & $\$ 41,00$ & 32 & 935 & 807.50 & $28 \quad 263$ \\
\hline$I A C-5603$ & 150,16 & 5 & 255 & 667.00 & 23 & 345 & 1102,25 & 38 & 579 & 630,00 & 22050 \\
\hline $\mathrm{F}$. & $5.63^{\prime}$ & & & $3,08 *$ & & & $6.81 \star$ & & & 2,60 & (Oos.) \\
\hline $\begin{array}{l}\text { D.M.S. } \\
(\text { Tuk日y }-5 \%)\end{array}$ & 64,67 & & & 346,43 & & & 395,09 & & & $n \cdot s$. & \\
\hline C.V. $(\because)$ & 28 & & & 31 & & & 22 & & & 26 & \\
\hline
\end{tabular}

Obs.: Significativo entro 10 e $5 \%$ de probabilidede.

*Baseado em 35000 plantas/ha.

$\mathrm{Na}$ tabela 15 apresentamos a relação peso de tubérculos no plantio e peso de tubérculos nos diferentes estádios do desenvolvimento. Este parâmetro frequentemente é utilizado na prática pelos agricultores para estimar o rendimento da produção.

Para que pudessemos situar as dados do trabalho com os obtidos durante anos de observação em ensaios de competição de cultivares no Estado de São Paulo elaboramos a tabela 16.

Os dados do trabalho, apresentados como observados, foram os obtidos aos 100 dias após a germinação; os calculados, através do ponto de máximo de equações ajustadas à partir dos dados observados (Expostas no ítem 4.4). Procedemos da maneira exposta, por julgarmos que o ajuste de equações de regressão representaria melhor o fenômeno da produção do que a amostragem executada na época isolada, uma 
vez que fomos impossibilitados de deixar plantas à parte dp canteiro para obtenção de dados finais de colheita. Reforçando o fato, temos os diferentes ciclos de maturação dos cultivares que poderiam ser prejudicados por comparação numa época estanque.

Tabela 15 - Relação peso de matéria fresca de aubérculo no plantio/colheita em diversas fases do desenvolvimento.

\begin{tabular}{llllll}
\hline \multirow{2}{*}{ Cultivar } & \multicolumn{5}{c}{ Dias após a germinação } \\
\cline { 2 - 3 } \cline { 5 - 6 } & 40 & 60 & 80 & 100 \\
\hline Aracy & $1: 1,5$ & $1: 7,4$ & $1: 11,2$ & $1: 9,6$ \\
Itaiquara & $1: 1,8$ & $1: 8,0$ & $1: 11,9$ & $1: 13,8$ \\
Abaetê & $1: 2,3$ & $1: 7,7$ & $1: 11,9$ & $1: 13,5$ \\
Teberê & $1: 1,2$ & $1: 6,8$ & $1: 11,4$ & $1: 14,0$ \\
IAC-55555 & $1: 0,9$ & $1: 6,1$ & $1: 11,8$ & $1: 10,1$ \\
IÁC-5603 & $1: 3,1$ & $1: 13,9$ & $1: 23,0$ & $1: 13,1$ \\
\hline
\end{tabular}

Na tabela 16 verificamos que os dados obtidos, em média, estão próximos dos encontrados nos ensaios de competição de cultivares realizados pela Seção de Raízes e Tubérculos, do Instituto Agronômico. O cultivar ITAIQUARA, é o único que se destaca dos demais por estar acima da média, porém se atentarmos para o intervalo de variação dos ensaios verificaremos que se aproxima do máximo obtido. Um desses valores máximo foi conseguido exatamente no município de Capão Bonito, S.P., em 1971, local do presente trabalho.

As variações de produção nos ensaios de competição se prendem ao fato de que os mesmos são realizados nas mais diferentes condições de solo, tratos culturais, épocas de plantio.

Na tabela 17 apresentamos um sumário das quantidades máximas produzidas e extraídas, respectivamente, de matéria seca e nutrientes pelos cultivares, obtidos junto às equações de regressão ajustadas.

Dos dados constantes na tabela anterior elaboramos a tabela 18 estabelecendo a relação matéria seca produzida por nutriente absorvido, como uma maneira de estimarmos, ainda que preliminarmente, a eficiência de absorção de nutrientes em função da matéria seca produzida pelos cultivares. Na mesma tabela os índices obtidos são comparados em porcentagem relativa tomando como base o cultivar ARACY.

A escolha da base de ponderação recaíu sobre esse cultivar dado ao fato do mesmo ser o mais conhecido, adaptado, de grande valor agronômico e o primeiro a ser fornecido em quantidade aos agricultores como "batata-semente. 
Os dados indicam que o cultivar IAC-5603 foi o mais eficiente, tanto para os nutrientes isoladamente, com exceção do enxofre, quanto para todos os micronutrientes somados. Isto talvez esteja relacionado mais com sua precocidade, já é um indicativo de eficiência, do que para eficiência de utilização propriamente dita.

De maneira análoga, o cultivar TEBERE, demonstrou ser o menos eficiente, apesar de ter sido um āos mais produtivos em termos de matéria fresca.

Tabela 16 - Produção de tubérculos obtida no trabalho e em ensaios de competição de cultivares realizados no Estado de São Paulo.

\begin{tabular}{|c|c|c|c|c|c|}
\hline \multirow{2}{*}{ Cultivar } & \multicolumn{2}{|c|}{$\begin{array}{l}\text { Produção de tubérculos } \\
\text { (média de } 4 \text { repetições) }\end{array}$} & \multicolumn{3}{|c|}{$\begin{array}{l}\text { Produção em ensaios de competição de } \\
\text { cultivares efetuados no Est. São Paulo* }\end{array}$} \\
\hline & Observada & Calculada & Variação & $\begin{array}{l}\text { Média e Inter- } \\
\text { valo de Con- } \\
\text { fiança }(5 \%)\end{array}$ & $\begin{array}{l}\text { N. }{ }^{\circ} \text { de } \\
\text { Ensaios }\end{array}$ \\
\hline & $\mathrm{kg} / \mathrm{ha}$ ** & $\mathrm{kg} / \mathrm{ha}$ ** & $\mathrm{kg} / \mathrm{ha}$ & $\mathrm{kg} / \mathrm{ha}$ & \\
\hline Aracy & 22619 & 19936 & $9000-45800$ & $21400 \pm 2800$ & 45 \\
\hline Itaiquara & 34738 & 37469 & $10400-32500$ & $22400 \pm 2900$ & 19 \\
\hline Abaetê & 19819 & 21344 & $14300-41000$ & $23100 \pm 6500$ & 10 \\
\hline Teberê & 25069 & 26520 & $12600-44200$ & $26000 \pm 7800$ & 9 \\
\hline IAC-5555 & 28263 & 24673 & $9500-43600$ & $26700 \pm 10160$ & 8 \\
\hline IAC-5603 & 22050 & 23524 & $10800-45900$ & $25100 \pm 11250$ & 7 \\
\hline
\end{tabular}

* FONTE: Arquivos da Seção de Raízes e Tubérculos - IAC, S.P.

** Baseado em 35000 plantas/ha.

Tabela 17 - Matéria seca total produzida e nutrientes extraídos pelos cultivares.

\begin{tabular}{lccccccc}
\hline \multirow{2}{*}{ Cultivar } & $\begin{array}{c}\text { Matéria } \\
\text { Seca }\end{array}$ & & $\mathrm{N}$ & $\mathrm{P}$ & $\mathrm{K} \quad \begin{array}{c}\mathrm{Ca} \\
(\mathrm{kg} / \mathrm{ha})^{*}\end{array}$ & $\mathrm{Mg}$ & $\mathrm{S}$ \\
\cline { 3 - 8 } & & & & 266 & 43 & 18 & 20 \\
\hline Aracy & 7860 & 163 & 23 & 266 & \\
Itaiquara & 7684 & 135 & 22 & 243 & 51 & 20 & 19 \\
Abaetê & 5111 & 102 & 13 & 168 & 48 & 16 & 17 \\
Teberê & 6896 & 165 & 16 & 264 & 80 & 25 & 25 \\
IAC-5555 & 9286 & 166 & 27 & 305 & 58 & 21 & 38 \\
IAC-5603 & 7979 & 123 & 18 & 223 & 37 & 16 & 31 \\
\hline
\end{tabular}

* Baseado em 35.000 plantas/ha. 
Tabela 18 - Relação matéria seca produzida (M.S., nutriente absorvido pelos diferentes cultivares.

\begin{tabular}{|c|c|c|c|c|c|c|c|}
\hline Cultivar & M.S. & M.S. & M.S. & M.S. & M.S. & M.S. & M.S. \\
\hline & $\mathrm{N}$ & $\mathbf{P}$ & $\mathrm{K}$ & $\mathrm{Ca}$ & $\mathrm{Mg}$ & $\mathrm{S}$ & $\Sigma$ Macron. \\
\hline Aracy & 48 & 342 & 30 & 183 & 437 & 393 & 15 \\
\hline Itaiquara & 57 & 349 & 32 & 151 & 384 & 404 & 15 \\
\hline Abaetê & 50 & 393 & 30 & 106 & 319 & 301 & 14 \\
\hline Iberê & 42 & 431 & 26 & 86 & 276 & 276 & 12 \\
\hline IAC- -5555 & 56 & 344 & 30 & 160 & 442 & 244 & 15 \\
\hline IAC-5603 & 65 & 443 & 36 & 216 & 499 & 257 & 18 \\
\hline Cultivar & \multicolumn{7}{|c|}{ Porcentagem Relativa } \\
\hline Aracy & 100 & 100 & 100 & 100 & 100 & 100 & 100 \\
\hline Itaiquara & 119 & 102 & 107 & 83 & 88 & 103 & 107 \\
\hline Abaetê & 104 & 115 & 100 & 58 & 73 & 77 & 93 \\
\hline Teberê & 86 & 126 & 87 & 47 & 63 & 70 & 80 \\
\hline IAC -5555 & 117 & 101 & 100 & 87 & 101 & 62 & 100 \\
\hline IAC-5555 & 117 & 101 & 100 & 87 & 101 & 62 & 100 \\
\hline IAC -5603 & 135 & 130 & 120 & 118 & 114 & 65 & 120 \\
\hline
\end{tabular}

De acordo com os resultados observados, como sugestão, aconselhamos que se verifique como um programa de estudos futuros, a resposta dos cultivares estudados aos fertilizantes, como uma forma de se aproveitar mais racionalmente o potencial de produção dos mesmos.

O trabalho teve como objetivo verificar as diferenças na acumulação da matéria seca, absorção e distribuição de nutrientes, entre os cultivares nacionais de batatinha: ARACY, ITAIQUARA, ABAETE ABATE, IAC-5555 e IAC-5603.

O experimento foi conduzido em concições de campo, de outubro de 1974 a janeiro de 1975, na Estação Experimental de Capão Bonito, do Instituto Agronômico do Estado de São Paulo, em solo do grande grupo Latossol Vermelho Escuro fase orto. Utilizou-se uma adubação $\mathrm{N}-\mathrm{P}_{2} \mathrm{O}_{5}-\mathrm{K}_{2} \mathrm{O}$ de $70-300-105 \mathrm{Kg} /$ ha de nitrogênio em cobertura 45 dias após.

As plantas foram amostradas durante o desenvolvimento da cultura em intervalos de 20 dias à partir da germinação até a seca das folhas . Analisou-se, na matéria seca, os teores de: nitrogênio, fósforo, potássio, cálcio, magnésio, enxofre, cobre e ferro. As curvas da marcha de absorção dos nutrientes e produção de matéria seca foram obtidas a partir de dados calculados por equações de regressão ajustadas. Considerou-se 
como quantidades evtraídas de nutrientes os pontos de máximo das equações ajustadas. O delineamento estatístico foi $o$ de blocos ao acaso .

\section{CONCLUSÕES}

Absorção de nutrientes

Os cultivares extraem quantidades diferentes de nutrientes. A extração de macronutrientes $(\mathrm{Kg} / \mathrm{ha})$ e micronutrientes $(\mathrm{g} / \mathrm{ha})$ é a seguinte:

N: IAC-5555 (166), TEBERE (165), ARACY (163), ITAIQUARA (135), IAC-5603 (123), ABAETE (102);

P: IAC-5555 (27), ARACY (23), ITAIQUARA (22), IAC-5603 (18), TEBERE (16), ABAETÊ (13);

K: IAC-(305), ARACY (266), TEBERE (264), ITAIQUARA (243), ABAETÊ (168);

Ca: TEBERE (80), IAC-5555 (58), ITAIQUARA (51), ABAETÊ (43), IAC-5603 (37);

Mg: TEBERE (25), IAC-5555 (21), ITAIQUARA (20), ARACY (18), IAC-5603 (16), ABAETE (16);

S: IAC-5555 (38), IAC-5603 (31), TEBERE (25), ARACY (20), ITAIQUARA (19), ABAETE (17);

Cu: ITAIQUARA (23), ARACY (20), TEBERÊ (19) ABAETÊ (17), IAC-5555 (17, IAC-5603 (16);

Fe: TEBERE (3 587), IAC-5555 (3 371), ITAIQUARA (2 823), ABAETÊ (2 709), ARACY (2 269); IAC-5603 (1 974);

Os cultivares diferem em relação às épocas de absorção para: fósforo, potássio, cálcio, enxofre e ferro. Quanto ao nitrogênio, magnésio, e cobre, as épocas de absorção são semelhantes, embora as quantidades extraídas sejam diferentes;

As diferenças na absorção dos nutrientes são mais acentuadas no início e no final do ciclo da cultura;

Exportação dos nutrientes

Os cultivares exportam quantidades diferentes de nutrientes através dos tubérculos. As quantidades exportadas de macronutrientes (kg/ha) e micronutrientes ( $\mathrm{g} / \mathrm{ha}$ ) é a seguinte: 
N: ARACY (81), ITAIQUARA (80), IAC-5555 (80), IAC-5603 (74), TEBERE (63), ABAETÊ (55);

P: ITAIQUARA (18), IAC-5555 (17), ARACY (15), TEBERRE (12), IAC-5603 (12), ABAETE (10);

K: IAC-5555 (159), ARACY (146), ITAIQUARA (142), IAC-5603 (140), TEBERÊ (104), ABAETÊ (98);

Ca: IAC-5555 (9,9), ARACY (7,5),IAC-5603 (7,1), TEBERE $(4,2)$, ITAIQUARA $(4,1)$, ABAETE $(3,6)$;

Mg: IAC-5603 (4,3), ARACY (4,0), IAC-5555 (3,9), ITAIQUARA $3,7)$, ABAETE $(2,8)$ TEBERE $(2,5)$;

S: IAC-5555 (21), IAC-5603 (21), ITAIQUARA (15), ABAETE (10), TEBERE (10), ARACY (9);

Cu: ITAIQUARA (17), ARACY (11), ABAETE (11), TEBERÊ (10), IAC-5603 (4), IAC-5555 (2);

Fe: ITAIQUARA (1 121), IAC-5603 (797), IAC-5555 (633), ARACY (598), ABAETE (381), TEBERE (273);

Produção de tubérculos

Os cultivares diferem na quantidade produzida de tubérculos;

As quantidades totais produzidas de tubérculos, em $\mathrm{Kg} / \mathrm{ha}$, são as seguintes ITAIQUARA (37 469), TEBERE (26520) IAC-5555 (24 673), IAC-5603 (23 524), ABAETE (21 344), ARACY (19 936);

O cultivar IAC-5603 é o mais precoce na produção de tubérculos;

Os cultivares ABAETE e TEBERÊ são os mais tardios.

SUMMARY

ACCUMULATION OF DRY MATTER, ABSORPTION AND DISTRIBUTION OF NUTRIENTS BY SIX BRAZILIAN POTATOES CULTIVARS

(Solanum Tuberosum L.).

The main object of the present study was to obtain information on the accumulation of dry matter, absorption and distribuition of nutrients by six potatoes cultivars (ARACY, ITAIQUARA, ABAETE, IAC-IIII, TEBERE, IAC-5603).

The experiment was conducted on a Red Dark Latossol at the Experimental Station in Capão Bonito, São Paulo. The experimental design utilized was a randonized complete block with four replications. Rates of nutrient utilized were as follows: $70 \mathrm{Kg} / \mathrm{ha}$ of $\mathrm{N} ; \mathrm{Kg} / \mathrm{ha}$ of $\mathrm{P}_{4} \mathrm{O}_{5}$ and $150 \mathrm{~kg} / \mathrm{ha}$ of $\mathrm{K}_{6} \mathrm{O}$ at planting time. All plots received an application of 70 $\mathrm{Kg}$ /ha of $\mathrm{N}$ in the dressin form, 45 days later. The stands corresponded to a population of 
35,000 plants perhectare. Sampling of the plants were executed at intervals of 20 days until maturity. Dry matter contents of leaves, stms and tubers were determined, as well as the concentration of $\mathrm{N}, \mathrm{P}, \mathrm{K}, \mathrm{Ca}, \mathrm{Mg}, \mathrm{S}, \mathrm{Cu}, \mathrm{Fe}$.

Dry matter content

- The cultivars presented different dry matter (KG/ha) content: IAC-5555 (9,286), IAC-5603 (7,979), ARACY $(7,860)$, ITAIQUARA $(7,864)$, TEBERE $(6,896)$ and ABAETE $(5,111)$.

- The maximum accumulation of dry matter took place betwenn 79 and 85 days after plants germinated.

Absorption of nutrients

Absorption of nutrients

- The cultivars absorved and accumlated different quantities of nutrients.

- The total absorption of macronutrients in $\mathrm{kg} / \mathrm{ha}$ was:

N - IAC-5555 (166), TEBERE (165), ARACY (163), ITAIQUARA (135), IAC-5603 (123), ABAETE (102).

P - 1AC-5555 (27), ARACY (23), ITAIQUARA (22), IAC-5603 (18), TEBERE (16), ABAET (13);

K - IAC-5555 (305), ARACY (266), TEBERE (264), ITAIQUARA (243), IAC-5603 (223), ABAETE (168);

Ca - TEBERE (80), IAC-5555 (58), ITAIQUARA (51), ABAETE (48), ARACY (43), IAC-5603 (37);

MG - TEBERE (25), IAC-5555 (21), ITAIQUARA (20), ARACY (18), IAC-5603 (16), ABAETE (16);

S - IAC-5555 (38), IAC-5603 (31), TEBERE (25), ARACY (20), ITAIQUARA (19), ABAETE (17);

- The total absorption of copper and iron in $g /$ ha was:

$\mathrm{Cu}$ - ITAIQUARA (23), ARACY (20), TEBERE (19), ABAETE (17), IAC-5555 (17), IAC-5603 (16);

$\mathrm{Fe}$ - TEBERE (3,587), IAC-5555 (3,371), ITAIQUARA $(2,823)$, ABAETE $(2,709)$, ARACY $(2,269)$, IAC-5603 $(1,974)$;

Exportation of nutrients

- Different quantities of nutrients were removed by the cultivar's tubers.

- The cultivars exported the following quantities of macronutrients in $\mathrm{kg} / \mathrm{ha}$;

$\mathrm{N}$ - ARACY (81), ITAIQUARA (80), IAC-5555 (80), IAC-5603 (74), TEBERE (63), ABAETE (55);

P - ITAIQUARA (18), IAC-5555 (17), ARACY (15), TEBERE (12), IAC-5603 (12), ABAETE (10);

K - IAC-5555 (159), ARACY (146), ITAIQUARA (142), IAC-5603 (140), TEBERE (104), ABAETE (98);

Ca - IAC-5555 (9,9), ARACY (7,5), IAC-5603 (7,1), TEBERE $(4,2)$, ITAIQUARA $(4,1)$, ABAETE $(3,6)$;

MG - IAC-5603 (4,3), ARACY (4), IAC-5555 (3,9), ITAIQUARA $(3,7)$, ABAETE $(2,8)$, TEBERE $(2,5)$;

S - IAC-5555 (21), IAC-5603 (21), ITAIQUARA (15), ABAETE (10), TEBERE (10), ARACY (9);

- The cultivars exported the following quantities of copper and iron in $\mathrm{g} / \mathrm{ha}$ : 


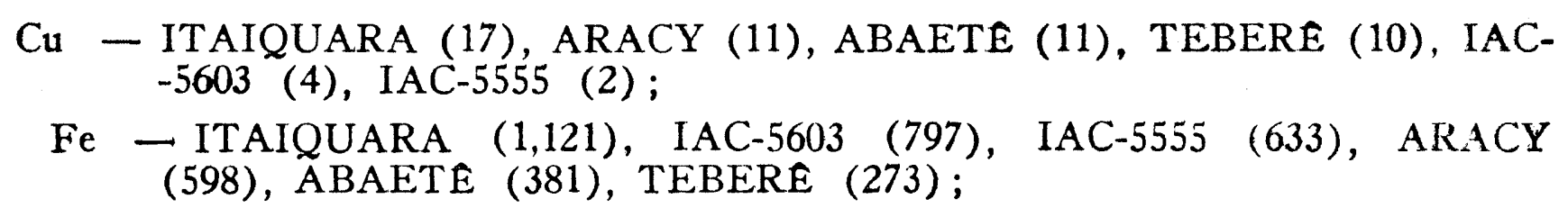

Tuberield uield

- The cultivars differs in tubers production;

- The total potatoes yield of the differents cultivars in $\mathrm{kg} / \mathrm{ha}$ were:

ITAIQUARA (37,469), TEBERE (26,520), IAC-5555 (24,673), IAC-5603 $(23,524)$, ABAETE $(21,344)$, ARACY $(19,936)$;

- The cultivar IAC-5603 was the first to ripe;

- The cultivars ABAETE and TEBERE were the latest to ripe.

\section{LITERATURA CITADA}

BATAGLIA, O.C. e J.R. GALLO, 1972. Determinação de cá cio e de magnésio em p âltas, por fotometria de chama de absorção. Bragantia. Campinas, 31:59-74.

BATAGLiA, O.C., 1975. Determinação indireta de enxofre em plantas por espectrolutometria de absorção atômica. Ciência e Cultura (no Prelo).

BONNER, J. e J.W. GALSTON, 1952. Principles of plant physiology. W.H. FREEMAN Co. San Francisco, USA. 499 p.

BOOCK, O.J. e J.E. PAIVA NETO, 1950. Produtividade e composição mineral de diferentes variedades de batatinha'. Bragantia. Campinas, 10:161-176.

BURTON, W.G., 1966. The potato: A survey of its history and of the factors influencing its yield, nutritive value, quality and storage. H. Veenman \& Zonen N.V. War geningen, Holland. $382 \mathrm{p}$.

BURTON, W.G., 1974. Requiriments of the users oif ware potatoes. P'otato Res. Lingland, $17: 374-409$.

CAMARGO, T. de C.A. KRUG, 1935. Experiências subre adubação da batata. Boletim técnico n. ${ }^{\circ}$ 16. IAC, São Paulo.

CARPENTER, P.N., 1957. Mineral accumulation in potato plants. Orono, Maine Agr. Exp. Stat.. Bull. N. ${ }^{\circ} 562.23$ p.

CAROLUS, R.L., 1937. Chemcial estimations of the weekly nutrient level of a potato crop. USA. Am. Potato J., 24(5):141-153.

CONCON, J.M. e D. SOLTESS, 1973. Rapid micro Kjeldahl digestion of cereal grains and others biological materials. USA, Analyt. Bioch. 53(1):35-41.

EZETA, F.N. e R.E. McCOLLUM, 1972. PRODUCTION de matéria seca y absorcion de nutrientes por Solanum andigena en los Andes Peruvianos. USA, A. Potato $I$., 49 (4) : 151-163.

GALlO, J.R., F.A.S. COELHO e S. de A. NOBREGA, 1965. Análise de folíclos, e pecíolos na diagnose da nutrição da batatinha. Campinas, Bragantia, $24: 385-401$.

GALLO, J.R., O.C. BATAGLIA, P.T.N. MIGUEL, 1971. Determinação de cobre, ferro, manganês e zinco, um mesmo extrato de planta por fotometria de chama de absorção. Campinas, Bragantia, $30: 155-167$.

GARGANTINI, H.G. BLANCO, J.R. GALLO e S. de NOBREGA, 1963 . Absorção de nutrientes pela batatinha. Campinas, Bragantia 22:267-290.

GARgAntini, H., S. de A. NOBREGA, L.S. Hungria, A.C. P. WUTKE, A. SCIVITTARO, e E.S. FREIRE, 1965. Adubação mineral da batatinha. II - Vale do Paraíba. Campinas, Bragantia, $24: 29-40$. 
GEHREKE, C.W., L.L. WALL e J.S. ABSHEER, 1973. Automated nitrogen method for fields. USA, J. Ass.; Off. Agric. Checm. 56(5): 1096-1105.

HAWKINS, A., 1942. Rate of nutrient absorption by different varieties of potatoes in Aroostook Country. Maine, E.I. du Pont de Nemours \& Co. Agric. News Lett. $10: 13-17$.

HAWKINS, A., 1946. Rate of absorption and translocation of mineral nutrients by potatoes in Aroostook Country, Maine, and their relation to practices. USA, J. Am. Soc. Agron. 38: 667-681.

HILL, H., 1953. Some aspects of fertilizer use for potato production and tuber quality. USA, Bett. Crops., $37(4): 11-16,46-50$.

HEWITT, E. J., 1963. The essencial nutrient elements: requeriments and interations in plants. In: Plant Physiology. F.C. Steward. Vol. III. Academic Press, New York, USA.

HIROCE, R., J.R. GALLO e S. de A. NOBREGA, 1971. Deficiência de boro em batatinha cultivada em solo orgânico do Vale orgânico do Vale do Paraíba. Campinas, Bragantia, 30 : nota V.

JACKSON, D.R. e J.L. HADDOCK, 1959. Growth and nutrient uptak of Russet Burbank Potatoes. USA, Am.. Potato J., 36(1):22-28.

KLAPP, E., 1950. Kartoffelban. Stuttgart: Eugen Ulmer, 31-40.

KUNKEL, R., N. HOLSTAD e R.C. HOLLAND, 1968. Problems of potato variety testing. USA. AMm. Potato J.. 45A11): 439.

KUNKEL, R., N. HOLSTAD e T.S. RUSSELL, 1973. Mineral element content of potato plants and tubers vs. yields. USA, Am. Potato J., 50(8):275-282.

KUPERS, I.J.P., 1975. Dry matter production of potatoes and uptake of nutrients at defferent stage of growth. $4 .^{\circ}$ Internacional Course on Potato Production. W ageningen. Holland. 12 p. mimeo.

LORENZ, O.A., 1947 Studies on potato nutrition III. Chemical composition and nutrients by County Potatoes. USA, Am. Potato J., 24(9) :281-293.

MUNTZ, e GIRARD, 1887. Les engrais. Vol. n. ${ }^{\circ}$ 3. Paris, France.

OKA, H., 1969. Studies on the productivity of potatoes in the Tolkachi District of Hokkaido National Agricultural Experimental Station, $95: 46-52$. In: Soil and Fertilizers, 1971, 34(1): 111 .

PERKIN-ELMER CORPORATION, 1971. Ed. Analytical Methods for Atomic Absortion Spectrophotometry. Nowalk, Connecticut, USA.

REMY, T., 1928. Handbuch des Kartoffelbaues. 2. Ed. Verlagsbuchhandlung Paul Bar rey Berlin, 31-45 p.

SARRUGE, J.R. e H.P. HAAG, 1974. Análises químicas em plantas. Piracicaba, EALAQ-USP. 52 p.

SCHMALFUSS, K., 1955. Pflanzenernahrung und Bodenkunde. Leipzig. S. Hirzel.

SMITH, O., 1968. Potatoes: Production, Storing, Processing Processing. The Avi Publ. Co. Inc. Westport, Connecticut, USA. $642 \mathrm{p}$.

SOLTANPOUR, P.N., 1969. Accumulation of dry matter and N, P, K, by Russet Burbank, Oromate and Red McCLURE Potatoes. USA, Am. Potato J., 46(4) : 111-119.

TAKAHASHI, H., s/data. Fertilizer recomendations for Japan. Tokyo. Kali. In: La fertilization de la Papa. G. GRUNER. 1963. Boletim Verde N. 17:10-13.

VINCENT, V., 1932. Fumore Rationnelle de la Pomme de Terre. Ministere de l'Agriculture, Paris. $3-24$ p. 
